Illinois State University

ISU ReD: Research and eData

Theses and Dissertations

$10-6-2015$

\title{
Exploring the Dark Side: Investigating the Relationship between Creativity and Perceptions of Dishonesty
}

Kiera Michelle Dymit

Illinois State University, kmfauth@ilstu.edu

Follow this and additional works at: https://ir.library.illinoisstate.edu/etd

Part of the Psychology Commons

\section{Recommended Citation}

Dymit, Kiera Michelle, "Exploring the Dark Side: Investigating the Relationship between Creativity and Perceptions of Dishonesty" (2015). Theses and Dissertations. 474.

https://ir.library.illinoisstate.edu/etd/474

This Thesis is brought to you for free and open access by ISU ReD: Research and eData. It has been accepted for inclusion in Theses and Dissertations by an authorized administrator of ISU ReD: Research and eData. For more information, please contact ISUReD@ilstu.edu. 


\title{
EXPLORING THE DARK SIDE: INVESTIGATING THE RELATIONSHIP BETWEEN CREATIVITY AND PERCEPTIONS OF DISHONESTY
}

\author{
Kiera M. Dymit
}

66 Pages

Previous studies have reported a connection between creativity and dishonesty (Beaussart, Andrews, \& Kaufman, 2013; Gino \& Ariely, 2012; Gino \& Wiltermuth, 2014). This study attempts to investigate these finding further, and empirically connect the number of justifications provided or produced for a dishonest behavior to the perceived acceptability of the behavior. 203 participants were given two tasks involving evaluating and justifying dishonest behavior. Those who scored high on the Creative Behavior Inventory were able to produce significantly more justifications overall, but not those who scored high on the Creative Personality Scale. The total number of justifications produced was correlated with the average perceived acceptability of dishonest behavior. However, when justifications were provided, they were not significantly correlated with the perceived acceptability of the dishonest behavior. Finally, this study was unable to find any significant connection between creativity and perceived acceptability of dishonest behavior, contrary to previous studies. Implications, limitations, and future directions are discussed.

KEYWORDS: Creativity, Dishonesty 
EXPLORING THE DARK SIDE: INVESTIGATING THE RELATIONSHIP BETWEEN CREATIVITY AND PERCEPTIONS OF DISHONESTY

KIERA M. DYMIT

A Thesis Submitted in Partial Fulfillment of the Requirements for the Degree of MASTER OF SCIENCE

Department of Psychology

ILLINOIS STATE UNIVERSITY 
(C) 2015 Kiera M. Dymit 
EXPLORING THE DARK SIDE: INVESTIGATING THE RELATIONSHIP BETWEEN CREATIVITY AND PERCEPTIONS OF DISHONESTY

KIERA M. DYMIT

COMMITTEE MEMBERS:

W. Joel Schneider, Chair

Michael J. Stevens 


\section{ACKNOWLEDGMENTS}

I know that I have many people to thank for their support, wisdom, and teachings. My chair, Dr. W. Joel Schneider has offered his time, incredible knowledge, and wisdom, not to mention his patience and dedication to the project. I'd like to thank Dr. Stevens for bringing structure and clarity to the study's main research questions, as well as his high standards and valuable assistance in the entire process. I would also like to thank Dr. Binning for his thoughtful feedback which challenged me and spurred me to work harder and to remain outside of my comfort zone. Additionally, I would like to thank Jackie Vermaat, Melanie Elsenbroek, and Haley Solem for their assistance in data collection. I would like to thank all of my graduate professors for their warm personalities, true teacher's hearts, and assistance through the entire program. Additionally, I'd like to thank my outstanding cohort for playing such a pivotal role in my development as a graduate student, a therapist, and a friend. Without the support of my family, I know that my life would not include this program. Choosing to leave everything behind and start a new career cannot be done alone. I have been truly blessed to have my family; James and Monica Dymit, my brother Brad, and my sisters, Sabrina and Gina. Finally, I am grateful to Kirk Lundeen for inspiring this project, encouraging me to continue working, reminding me of my value, and teaching me to embrace the moment.

K.M.D. 


\section{CONTENTS}

Page

ACKNOWLEDGMENTS $\quad$ i

CONTENTS

TABLES $\quad$ iv

FIGURES

CHAPTER

I. PROBLEM STATEMENT AND PURPOSE 1

Statement of the Problem 1

Purpose of This Project 3

II. REVIEW OF RELATED LITERATURE 4

Creativity 4

Development of Moral Theory $\quad 7$

Mind Perception $\quad 8$

$\begin{array}{lr}\text { Moral Disengagement } & 9\end{array}$

$\begin{array}{ll}\text { Creativity and Morality } & 13\end{array}$

$\begin{array}{ll}\text { Research Questions and Hypotheses } & 14\end{array}$

$\begin{array}{ll}\text { III. METHOD } & 17\end{array}$

$\begin{array}{ll}\text { Participants } & 17\end{array}$

$\begin{array}{ll}\text { Measures } & 19\end{array}$

Creativity Personality Scale $\quad 19$

Creative Behavior Inventory $\quad 20$

Controlled Oral Word Association Test $\quad 21$

Balanced Inventory of Desirable Responding $\quad 22$

International Personality Item Pool 24

$\begin{array}{ll}\text { Procedure } & 25\end{array}$ 
Assessment Tasks $\quad 30$

Demographics $\quad 30$

Debriefing $\quad 30$

IV. RESULTS 31

Descriptive Statistics 31

Hypothesis One $\quad 31$

Hypothesis Two $\quad 32$

Hypothesis Three $\quad 36$

Hypothesis Four $\quad 39$

V. DISCUSSION 41

$\begin{array}{ll}\text { Conclusions } & 41\end{array}$

Hypothesis One $\quad 41$

Hypothesis Two $\quad 42$

Hypothesis Three $\quad 43$

Hypothesis Four $\quad 44$

Limitations and Future Directions 45

$\begin{array}{ll}\text { REFERENCES } & 49\end{array}$

APPENDIX A: Questionnaires 57

APPENDIX B: Letter of Introduction and Informed consent 64

APPENDIX C: Debriefing Statement 66 


\section{TABLES}

Table $\quad$ Page

1. Demographic Data Frequencies and Percentages 18

2. Means, Standard Deviations, and Conbach $\alpha$ Coefficients for All Measures Used and Acceptability Ratings

3. Ordered Logistic Regression Coefficients for the Polynomial Effects of Justification Exposure and Evaluation on the Perceived Acceptability of Dishonest Behavior in Task 2

4. Correlations of Creativity and Perceived Acceptability of Dishonest Behavior

5. Ordered Logistic Regression Coefficients in Task 2

6. Path Analysis of Task 1 Variables with Standardized Variables and Interaction Terms 


\section{FIGURES}

Figure $\quad$ Page

1. Conceptual Model for Hypotheses 15

2. Conceptual Model for Hypothesis $2 \quad 15$

3. Mean Task 2 Perceived Acceptability Ratings as a Function of the Number of Justifications for Dishonesty

4. Model-Implied Response Probabilities When Number of Justifications Predicts the Perceived Acceptability of Dishonest Behavior in an Ordered Logistic Regression Model

5. Path Analysis of the Task 1 Variables

6. Model-Implied Response Probabilities When Number of Justifications and Impression Management Predicts the Perceived Acceptability of Dishonest Behavior in an Ordered Logistic Regression Model 


\section{CHAPTER I}

\section{PROBLEM STATEMENT AND PURPOSE}

\section{Statement of the Problem}

To many in Western culture, creativity is seen as a positive trait to be fostered and nurtured. Successful companies strive to find innovative thinkers and creative personalities to help gain an edge against the competition (Shalley, Zhou, \& Oldham, 2004). School children are taught that George Washington's creative use of his small militia led to the success of the Revolutionary War. In academia, the ability to create and synthesize new information from old is considered the highest level (and ultimate goal) of critical thinking skills (Krathwohl, 2002). Despite creativity's value and positive qualities, negatives also exist. True to the saying that "there are two sides to every coin," creativity does indeed have a dark side.

The dark side of creativity includes evidence that some creative people may be more likely to be dishonest. In a series of studies, Gino and Ariely (2012), found that scores on creative personality measures and dishonesty are positively correlated. They also found that being primed to think creatively increases the likelihood of engaging in dishonest behavior. When given opportunities to justify dishonest behavior, both creative and non-creative groups behaved equally dishonestly, but when opportunities to justify behaviors were low, creative people were more dishonest than non-creative people (Gino \& Ariely, 2012). Beaussart et al. (2013) supported this connection between creativity and 
dishonesty with a study of their own, reporting that people who scored high on creativity measures were more likely to cheat by taking extra credit that they had not earned.

The relationship between creativity and dishonesty also seems to be a two-way street. Not only were people more likely to behave dishonestly when they were primed to think creatively, (Gino \& Ariely, 2012), but people who behaved dishonestly in another study (Gino \& Wiltermuth, 2014) were subsequently more creative, even after accounting for creative differences. If dishonesty and creativity were cousins, their common relative would appear to be divergence, or rule-breaking, as participants who engaged in dishonest and creative tasks described feelings of being unconstrained by rules (Gino \& Wiltermuth, 2014).

Gino and Ariely (2012) explain that their findings are evidence that creativity may increase a person's ability to generate reasons to justify their behavior, thus promoting dishonesty. Specifically, they put participants in a position in which they were able to lie in order to earn more money from the study. They were randomly placed into conditions that either allowed for or limited opportunities to create justifications for lying. It was found that the group with more opportunities to justify lying was more likely to lie. Additionally, some creative people were more likely to lie than non-creative people when there were fewer opportunities to justify the behavior, but that difference was not found in the condition allowing for more justifications. Their conclusion from these findings is that "creativity promotes dishonesty by increasing individuals' ability to generate reasons to justify their dishonest behavior" (Gino \& Ariely, 2012, pp. 22).

However, the participants were not specifically asked if they made any justifications at all, nor were the number of justifications made tallied. Additionally, it 
was not measured if justifications themselves are what promote dishonesty. So, while we can reasonably infer that more justifications were made and that more justifications promote dishonesty, this current study was designed to further clarify these findings. It looks into whether creative people actually do produce more justifications, and if the number of justifications provided for dishonesty affects a person's view of dishonest behavior.

\section{Purpose of This Project}

This project aims to look more closely at the mechanisms that connect creativity with dishonest behavior. Gino and Ariely (2012) suggest that creativity may help people generate various reasons to justify dishonest actions that they see as credible, and that the more easily justifications can be produced, the more likely someone will behave dishonestly. These justifications can serve as a mechanism for minimizing the perceived negative elements of the action, allowing one to morally disengage (Bandura, 1999). Gino \& Ariely's study found that when given opportunity to create justifications, those who were primed for creativity were not more likely to behave dishonestly than those who were not, but that creative personality led to greater likelihood of dishonestly, with or without opportunities for justifications (Gino \& Ariely, 2012). The driving logic behind previous researchers' connection between creativity and dishonesty (Gino \& Ariely, 2012) is that no matter how creative a person is, if a large number of credible justifications are provided for a dishonest behavior, a person is more likely to condone it, and that creative people are able to produce more justifications, even when they have fewer opportunities to do so. This possibility has been suggested by researchers, but to date no research has been done to empirically investigate this specific idea. 


\section{CHAPTER II}

\section{REVIEW OF RELATED LITERATURE}

\section{Creativity}

As described in the introduction, creativity is the focus of this study, and at first glance, it may seem like a well-understood term. The average person is likely to use the word creativity in their everyday language. Children are praised for being creative in their art projects, people are complimented on their creative room decorations, and employers often describe a way of completing a task at work as creative. Generally speaking, it would seem that most people share a common meaning of creativity. However, when it comes to defining creativity for the purposes of scientific research, the definition is a little harder to pin down. For example, should creativity be measured based on past achievements, self-perceptions, thought processes, task performance, or something else entirely? Also, how does one determine if an activity is especially creative? Experts? How should one determine who a creative expert is? Should it be by number of creative achievements or notable creative achievements, or something else? Because there are so many dimensions of creativity and many different ways to operationalize it, research on "creativity" may, in fact, address very different aspects of creativity, sometimes producing results based on very different criteria. 
A working definition of creativity for this project is the rendering of original ideas, original working and thinking processes, and original products (Barron, 1955; Simonton, 2003), and the ability to produce novel ideas that are also adaptive. (Amabile, 1988; Runco \& Jaeger, 2012). Based on research by Gino and Ariely (2012), this project will be measure creativity using a person's own view of their creativity (how would they describe themselves), and how many creative achievements they have completed in their lifetime. This certainly does not encompass all of the ways creativity can be measured, and these measurements can be applied in several different ways to define creativity, but it is a reasonable place to start because this definition includes elements of both divergence and flexibility that appear repeatedly in scholarly descriptions of and research regarding creativity (Amabile, Conti, Coon, Lazenby, \& Herron, 1996; Barron, 1955; Beaussart, Andrews, and Kaufman, 2013; Getzels \& Jackson, 1962; Gino \& Ariely, 2012; Gino \& Wiltermuth, 2014; Guilford, 1975; Silvia, 2008; Simonton, 2003; Torrance, 1959; Wallach \& Kogan, 1965).

One characteristic of creativity that is of interest in this project is an ability and willingness to bend or break established structures in a way that produces desirable outcomes. The creative person sees the guidelines presented for a particular task and is willing to be flexible to achieve oftentimes not only the original goal, but also selfexpression (Getzels \& Jackson, 1962). Creative people possess fluid, flexible thinking and produce original ideas that are appropriate for the situation (Amabile, Conti, Coon, Lazenby, \& Herron, 1996; Torrance, 1959). This willingness and flexibility may play a role in a creative person's tendency towards dishonesty. 
The Structure of Intellect Model (Guilford, 1975) offers a bit of background that may explain some of the creativity/dishonesty connection. In this model, divergent thinking, the ability to think of unique answers to a question, is thought to be a key precursor to creativity (Guilford, 1975). That is, the creative thinker has original ideas, new perspectives on existing ideas, and more ideas in general (Silvia, 2008; Wallach \& Kogan, 1965). Sometimes included in divergent thinking are dishonest solutions to problems.

Creative people remain open to the world, willing and able to see things differently than others, including those of authority and those whom they care for. Creativity has been found to have a positive relationship with openness to experience scores on the NEO (Baer \& Oldham, 2006; Feist, 1998; Shalley et al., 2004). Creative people's ideas are not bound by the conventional, giving them a tendency to satisfy desires that are traditionally inhibited (Getzels \& Jackson, 1962), and a likelihood to do so through dishonest means (Gino \& Ariely, 2012).

Some scholars believe that creativity is about cognitive flexibility as well as divergent thinking (Spiro \& Jehng, 1990). While divergent thinking involves producing a higher number of ideas as well as more original and complex ideas (Guilford, 1975; Silvia, 2008; Wallach \& Kogan, 1965), cognitive flexibility is the ability to adapt to people, situations, and environments by restructuring knowledge (Rende, 2000). Flexibility in one's thinking can help solve problems (Mumford \& Gustafson, 1988), allowing someone to "roll with the punches" of life, so to speak. In other words, a creative person may have a wider arsenal of coping strategies (Runco, 2004), and a stronger ability to think beyond the confines of one's preconceptions (Ward, Thompson, Lake, Ely, \& Kaminski, 2008). The 
extension of this idea is the question of whether a creative person will be just as apt to think divergently and be flexible with acceptance of dishonesty.

\section{Development of Moral Theory}

The goal of this project is to understand more about why some creative people are more dishonest, and so, it is useful to get an understanding of why people in general may be dishonest or where our ideas about honesty come from in the first place. Definitions of and theories related to morality are as diverse as those on creativity. However, a survey of current theories about morality will reveal certain commonalities that are uncontroversial. One of these is the idea that emotions play an especially important role in moral development, moral persuasion, and moral decision making (Gaudine \& Thorne, 2001; Haidt, 2001; Haidt, 2012; Haidt, Koller, \& Dias, 1993; Pizarro, 2000).

The Moral Foundations Theory (Haidt, 2001) builds on the idea of social intuitionism. In contrast to Kohlberg's (1977) emphasis on cognitive processes in moral reasoning, Moral Foundations Theory argues that at their core, moral judgments, actions, and beliefs involve a primarily emotional process, with an interaction between emotions and rationalizations. When one comes across a situation in which a moral judgment can be made, an initial emotional reaction takes place based on instinctual values developed through a combination of biological and cultural evolutionary processes. Following the initial emotional reaction, a person will often rationalize his or her judgment, typically via unconscious processes (Haidt, 2001; Haidt, 2012; Haidt et al., 1993). Haidt theorizes that rationalizations are produced after moral judgments in order to support the preceding emotions, rather than before, and that moral judgments are not dependent on whether or not rationalizations successfully explain their emotions (Haidt, 2012; Margolis, 1987). 
However, a more "chicken or the egg" relationship may exist, where emotions serve as motivations to produce justifications, and justifications alter moral emotions. The connection can be seen if a person with creative tendencies is to be able to produce justifications that allow them to manipulate their own emotions to more readily justify dishonesty. Creative people may be using superior divergent thinking skills and cognitive flexibility to persuade themselves to feel less morally convicted about dishonest behaviors.

\section{Mind Perception}

The interaction between cognitions and emotions is just one element involved in moral decisions. The interaction between people and even how we perceive people is worth investigating in connection to morality. It is not immoral for a person to get great joy out of kicking a soccer ball, but finding great joy in kicking a baby certainly is. Gray, Young, \& Waytz (2012) argue that the difference between the two actions, and the essence of morality itself, comes down to "mind" perception. The use of the word "mind" refers to an understanding of and empathy towards the emotions, perceptions, and feelings of another. While we may have a sense of our own mind, we cannot objectively measure the existence of another's mind. Sure, a friend can tell us that he is hurting or what he is thinking, and it is this that allows us to infer that he has a mind, but even brain scans and self-report measures offer only an indirect access into the mind, making it ultimately a matter of perception. It is when we perceive the minds of others that we can then work to understand what that mind is thinking, feeling, or desiring. If we view others as having a mind, then we can develop empathy for others, see them and ourselves as moral agents, and attribute moral rights and responsibilities to them (Bastian, Laham, 
Wilson, Haslam, \& Koval, 2011; Gray et al., 2012). In other words, when we perceive the mind of another, we are more likely to treat others as we would want to be treated.

Oftentimes, mind perception is not about whether or not a mind exists (e.g., rock vs. baby), but it is about deciding which agents deserve how much of our concern or moral intention - who or what we include in our "moral circle" (Pizarro, DetweilerBedell, \& Bloom, 2006). Attributing (or not attributing) agency, that is, a "mind", to someone has been shown to affect the perception of one's morality. If a person is able to deny to oneself that another has agency and is able to dehumanize the other in some way, they can effectively exclude that person from their moral circle, and then even harmful acts against him or her can be justified (Bandura, Barbaranelli, Caprara, \& Pastorelli, 1996; Cikara, Eberhardt, \& Fiske, 2011; Gray \& Wegner, 2009; Gruenfeld, Inesi, Magee, \& Galinsky, 2008; Harris \& Fiske, 2011).

The idea that morality is not just a cognitive exercise in reasoning as once thought (Kohlberg, 1977) but a flexible process involving interactions between both cognitions and feelings (Haidt, 2001; Pizarro, 2000) opens up the concept that deciding who/what to value morally, how to behave, and how we justify what we do involves more than just logic and can be influenced by our emotions, social environments, cultural histories, and personality traits - including creativity.

\section{Moral Disengagement}

To understand how a creative person may possess greater ability to manipulate his or her moral circle, it is important to understand how it is done in general. Bandura's Social Cognitive Theory (1991) explains that the moral standards of an individual and/or society are formed not by using logic and reasoning to analyze potential benefits and 
drawbacks alone. The theory proposes that it also includes the processes of observing how behaviors inflict suffering on others, what levels of suffering are present for actions (which can vary from action to action and individual to individual), how circumstances and intentions affect the perceived acceptability of certain actions, and how others are perceived. This affects how much it matters to someone if their actions bring harm. People may be capable of moral reasoning, but until they give agency to those around them, they are not going to act morally (Bandura, 1991).

A person faces a moral dilemma when he or she wishes to behave in a selfserving manner, but in doing so would be potentially harmful, as is the case with being dishonest. Engaging in potentially harmful behavior could affect not only others' view of the person, but also his or her self-image. A person is likely to make a compromise of sorts; to behave "a bit" dishonestly to satisfy the self-serving desire, but not so much so as to affect ones positive self-image and moral reputation (Mead, Baumeister, Gino, Schweitzer, \& Ariely, 2009). By behaving “just a little” dishonestly, a person provides oneself the opportunity to produce justifications for the dishonest behavior (Ayal \& Gino, 2012; Gino, Ayal, \& Ariely, 2009). For example, in one study, people selling a car were given the option to provide an estimation of mileage to the buyer based on a range. They found that the wider the range, the more likely the seller was to lie about the mileage, justifying the lie through the larger amount of uncertainty (Schweitzer \& Hsee, 2002). It would seem that the better skilled a person is at producing what they believe are reasonable justifications for dishonesty, the more likely they are to subscribe to them (Kunda, 1990). If someone is able to morally disengage, or in other words, separate one's emotions and ideas about right and wrong from one's own conduct, the likelihood of 
aggressive and harmful behaviors is heightened (Bandura, Underwood, \& Fromson, 1975; Diener, 1977; Diener, Dineen, Endresen, Beaman, \& Fraser, 1975; Haney, Banks, \& Zimbardo, 1973; Milgram, 1974; Tilker, 1970). Essentially, when people morally disengage, they convince themselves that the rules do not apply specifically to them in their specific situation. This is where the connection to creativity can be made in that a creative person may be more skilled at producing more, and more convincing, justifications.

According to Bandura (1996), there are many ways that a person can justify engagement in behavior they would normally see as wrong, such as dishonesty. Tilker (1970) found that when a person is made fully responsible for the safety of another, and they are receiving both visual and auditory feedback from that person, they are more likely to behave in a socially responsible manner towards him or her (Tilker, 1970). This supports the idea that moral behavior hinges on both seeing oneself and others as a human being with thoughts, feelings, and value.

Another method of moral disengagement is to choose to view a harmful or immoral behavior as something that furthers a good, moral cause, or as required for selfdefense (Bandura, 1996; Kelman, 1973; Kelman \& Hamilton, 1989; Kramer, 1990; Smelser, 1971). Also, language is a powerful tool in justifying behavior. Rewording things to seem "better" can be powerfully disinhibiting (Bandura, 1996; Diener et al., 1975) and can make behaviors seem less reprehensible or even respectable (Bolinger, 1980; Lutz, 1987). Examples of this in everyday life include telling a "white lie" rather than deceiving, "venting" rather than gossiping, or "borrowing" rather than stealing. 
Another way that a person may justify harmful or immoral behaviors is through displacing or diffusing responsibility (Bandura, 1996, 1999). For example, a person may believe that because they only participated in one small part of something immoral, what they had done was done was not actually wrong. This moral disengagement was seen among many involved in The Holocaust, explaining that they, for example, only transported prisoners, kept records, or so on (Andrus, 1969). Similarly, if a dishonest behavior becomes routinized and divided across several people or departments, it becomes easier for a person to justify it, allowing them to see even acts of murder as "all in a day's work" (Kelman, 1973).

In the study by Diener et al. (1975), people were found to be almost 38 times as aggressive when they believed they were not going to be held accountable for their behavior, observed a model enacting aggressive behavior, or were put into a mindset to see their aggressive behaviors as a game (Diener, et al., 1975; Milgram, 1974).

Another way that someone may create justification for immoral behaviors is through dehumanization. The act of dehumanization changes patterns of thought and changes the view of the person to one with diminished or no feelings, hopes, needs or concerns (Duster, 1971; Keen, 1986; Kelman, 1973). When dehumanization occurs, it becomes more likely that a person will create moral justifications for aggressive or harmful actions against the dehumanized individual (Bandura et al., 1975; Duster, 1971; Milgram, 1974). History has shown that moral disengagement has contributed to crimes against humanity (Andrus, 1969; Keen, 1986; Kelman, 1973; Kelman \& Hamilton, 1989; Rapoport \& Alexander, 1982; Reich, 1990). When given an opportunity to justify selfserving or dishonest behaviors, a person is more likely to engage in the dishonesty than 
when not given the opportunity for justifications (Schweitzer \& Hsee, 2002; Shalvi, Handgraaf, \& De Dreu, 2011; Snyder, Kleck, Strenta, \& Mentzer, 1979). If a creative person is able to produce opportunities for justification and moral disengagement, this may explain the positive relationship between creativity and dishonesty.

\section{Creativity and Morality}

Haidt and colleagues have made the case that morality and moral judgments are in many ways socially driven (Haidt, 2001, 2012; Haidt et al., 1993) and are affected by our perceptions of others as well as our emotions towards them (Haidt, 2012; Miller, 1997; Pizarro et al., 2006; Rozin, Haidt, \& McCauley, 2000). We have also learned that creative people are capable of taking what they are given and producing new ideas, conclusions, and products, often with the effect of persuading others to view ideas and situations differently (Pizarro et al., 2006; Runco \& Jaeger, 2012; Silvia 2008; Simonton, 2003; Torrance, 1959;). Thus, it seems plausible that creative people are more likely to be able to manipulate the cognitive and emotional interaction, shaping and re-directing empathy and related emotions when making moral decisions so as to justify what would otherwise seem immoral, such as dishonesty.

Pizarro et al. (2006) propose that throughout history, it was those who resonate with and sway others' emotions - the poets, public speakers, politicians, musicians, and artiststhat challenged and changed the moral beliefs of individuals and societies. Through creative uses of language, images, stories, songs, and movies, the shifting of the ideas on right and wrong is influenced by emotions. Gino and Ariely (2012) found that when someone is

primed to think creatively, they are more likely to behave dishonestly. They suggest that this is because creative people are able to generate more justifications, making the dishonesty 
more likely to occur. For the creative person, an ethical dilemma poses a difficult situation for which they may have a unique set of skills that allow them to produce creative solutions. When problems are difficult, a creative person's cognitive flexibility combines with divergent thinking to create a fertile environment for a justification process favoring selfserving conclusions, and ultimately, moral disengagement (Gino \& Ariely, 2012).

\section{Research Questions and Hypotheses}

The primary purpose of this study is to clarify the nature of the relationship between dishonesty and creativity. It is possible that creative people will generate more justifications for dishonest behavior than less creative people. If this is true, it is perhaps the mere exposure to more justifications for dishonesty that results in more dishonest behavior. For this study, justifications are defined as statements or ideas that lesson the perceived harm an action causes, or perceived moral wrong committed (Haidt 2001, Hauser, 2006; Hauser et al., 2007).

This line of reasoning rests on two assumptions. First, that creative people are able to generate more justifications for dishonest behavior, and second, that generating more justifications for dishonesty tends to make people more tolerant of their own dishonest behavior. Based on these ideas, four hypotheses were developed:

Hypothesis 1: Scores on creativity measurements will be correlated with numbers of justifications produced for dishonest behavior (Figure 1). 


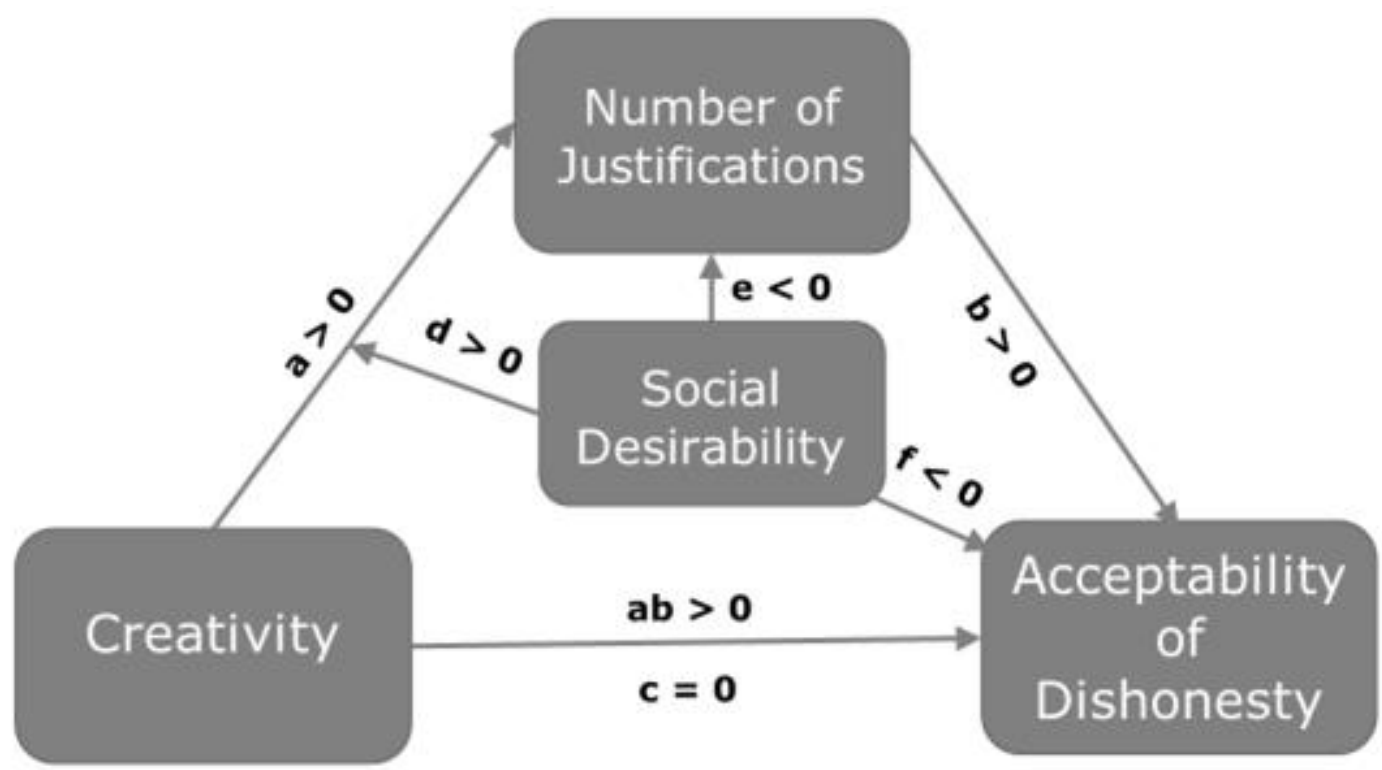

Figure 1. Conceptual Model for Hypotheses.

Hypothesis 2: The number of justifications for a dishonest behavior will be correlated with the perceived acceptability of the behavior, supporting the idea that it will be more likely for someone to engage in the behavior (Figure 1 and Figure 2).

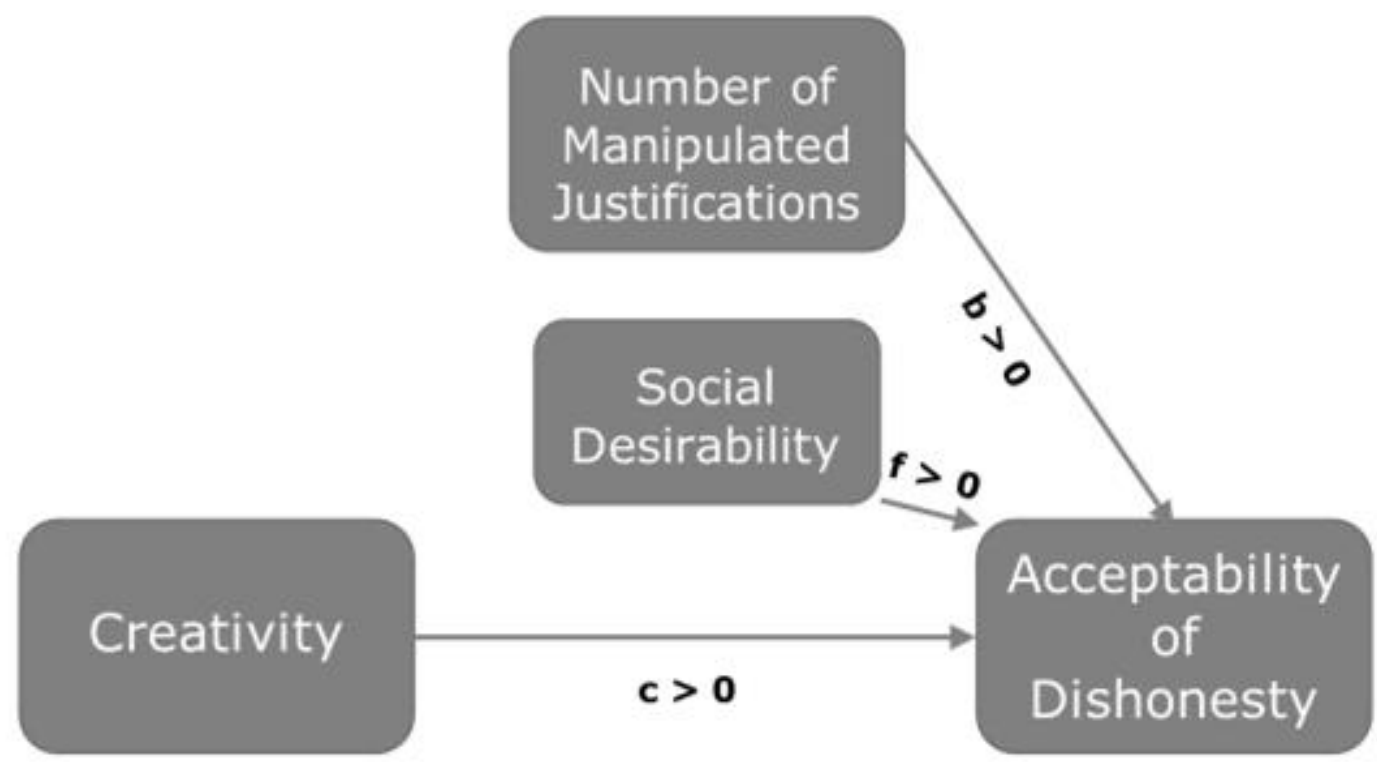

Figure 2. Conceptual Model for Hypothesis 2. 
Hypothesis 3: The number of justifications for a dishonest behavior will act as a mediator between creativity and the perception of acceptability of the behavior (Figure 1).

Hypothesis 4: Social desirability scores on the Balanced Inventory of Desirable Responding (BIDR) measure will moderate the relationship between creativity and the number of justifications. Although not a focus of this study, it is expected that the BIDR will have a negative correlation with the perceived acceptability of dishonesty (Figure 1). 


\section{CHAPTER III}

\section{METHOD}

\section{Participants}

A total of 205 people participated in this study. Data from two participants were excluded; one participant did not speak English fluently, and the other appeared to be under the influence of mind-altering substances. This left a final sample of 203 participants between the ages of $18-46(M=19.6, S D=2.6)$. The participants were asked to indicate their age, sex, ethnicity, GPA, and estimated parental income. Table 1 summarizes these demographic variables. All participants gave written informed consent. The procedure was approved by the Institutional Review Board at Illinois State University. Participants were selected from the Illinois State University Psychology Research Participant Pool. 
Table 1

Demographic Data Frequencies and Percentages

\begin{tabular}{|c|c|c|}
\hline Variable & Frequency & Percent \\
\hline \multicolumn{3}{|l|}{ Age } \\
\hline 18 & 69 & 34.0 \\
\hline 19 & 54 & 26.6 \\
\hline 20 & 45 & 22.2 \\
\hline 21 & 18 & 8.9 \\
\hline $22-29$ & 15 & 7.3 \\
\hline $30-34$ & 1 & .5 \\
\hline $45-49$ & 1 & .5 \\
\hline \multicolumn{3}{|l|}{ Gender } \\
\hline Male & 38 & 18.7 \\
\hline Female & 165 & 81.3 \\
\hline \multicolumn{3}{|l|}{ Race/Ethnicity } \\
\hline African-American & 12 & 5.9 \\
\hline Native American & 1 & .5 \\
\hline East Asian & 1 & .5 \\
\hline South Asian & 2 & 1.0 \\
\hline White (not Hispanic) & 170 & 83.7 \\
\hline Other & 1 & .5 \\
\hline \multicolumn{3}{|l|}{ GPA } \\
\hline $1.5-1.99$ & 3 & 1.5 \\
\hline $2.0-2.49$ & 4 & 2.0 \\
\hline $2.5-2.99$ & 27 & 13.3 \\
\hline $3.0-3.49$ & 61 & 30.0 \\
\hline $3.5-3.74$ & 50 & 24.6 \\
\hline $3.75-3.99$ & 35 & 17.2 \\
\hline 4.0 & 20 & 9.9 \\
\hline Missing & 3 & 1.5 \\
\hline \multicolumn{3}{|l|}{ Parent Income } \\
\hline Less than $\$ 5000$ & 1 & .5 \\
\hline$\$ 5000-\$ 20000$ & 11 & 5.4 \\
\hline$\$ 20000-\$ 60000$ & 46 & 22.7 \\
\hline$\$ 60000-\$ 100000$ & 70 & 34.5 \\
\hline$\$ 100000-\$ 150000$ & 46 & 22.7 \\
\hline$>\$ 150000$ & 26 & 12.8 \\
\hline Missing & 3 & 1.5 \\
\hline
\end{tabular}




\section{Measures}

Measures were chosen to parallel the instruments used by Gino and Ariely (2012) in their research on the relationship between creativity and dishonesty. Two creativity assessments were chosen.

\section{Creativity Personality Scale}

Gough's Creative Personality Scale (Gough, 1979) is a self-report measure of creativity as a part of the Adjective Check List. It is a 30-item self-report survey of various personality characteristics. The survey was originally developed to be used by observers in describing others, but evolved into a self-report measure. The checklist asks participants to select adjectives from a list that describes their personality, but can also be used to identify a person's ideal self, beliefs, values, ideal mate or almost anything else the adjectives could describe.

The current version of the checklist has 37 different subscales, one of which is Creative Personality. The Creative Personality Scale of the Adjective Checklist asks participants to read a list of 30 adjectives and select the ones that best describe them. Some of the adjectives on the list relate to creativity (e.g., insightful, original, unconventional), and the participants receive a point for every one of the creativity-tied adjectives that they select.

To develop the Creativity Personality Scale itself, the Adjective Checklist was administered to 1,701 individuals from a wide range of ages and careers, all with direct or inferred ratings of creativity available for the individuals. An item analysis was completed of the six different scales of the checklist that had been previously established as measures of creativity (Schaefer, 1972, 1973; Smith \& Schaefer; 1969; Welsh, 1977), 
and found that 30 items were positively and significantly $(p<.01)$ correlated with those six scales. These 30 items became the Creativity Personality Scale. For this scale, $\alpha$ coefficients ranged between .73 and .81 .

Even while using samples from a wide range of careers, ages, and testing circumstances and employing four different perspectives on creativity (expert judges, faculty members, personality-assessment staff observers, and life-history interviewers), 10 out of 12 of the validity coefficients were significant $(p \leq .05)$. The criteria chosen were the Domino creativity measurement, the Schaefer creativity measurement, Welsh origence/intellectence (high/low combinations of both origence and intellectence), rating by expert judges, ratings by faculty members, ratings by assessment staff, and rating by interviewers.

\section{Creative Behavior Inventory}

Another creativity measure used in Gino and Ariely's (2012) research was Hocevar's Creative Behavior Inventory (Hocevar, 1980). Participants were presented with a list of accomplishments and activities that are associated with creativity (e.g., wrote an original computer program not for school or university work, painted an original picture not as a part of school or university work). The participants then indicated whether they had done each of the activities or accomplishments in their adolescent and adult life never, once or twice, 3-5 times, or more than 5 times. To score, a sum of the participant's ratings is calculated.

The Creative Behavior Inventory was developed initially by asking college students to list their most creative achievements. Experts rated the list that was produced, and the items that received the lowest ratings were removed. 90 items were developed. 
The inventory was used in other studies, finding that several Creative Behavior Inventory subscales correlate with ideational fluency. The internal consistency of the Creative Behavior Inventory overall is .91 (Dollinger, Urban, \& James, 2004). The measurement items were also originally grouped into six categories (literary accomplishments, performance arts, crafts, music, and math/science). With the exception of math and science, all of the categories halve Cronbach $\alpha$ coefficients ranging between .75 and .87 . The math and science category has a Cronbach $\alpha$ coefficient of .53 (Dollinger et al., 2004). In the current study, the Cronbach $\alpha$ for the total scale of the Creative Behavior Inventory was .89 .

If the two measures of creativity are measures of the same aspect of creativity, they should have robust correlations with each other. In the study by Gino and Ariely (2012), the correlation between the Creative Behavior Inventory and the Creative Personality Scale varied from experiment to experiment from .33 to .45 . In the current study, the correlation between scores from the Creative Behavior Inventory and the Creative Personality Scale was $r(203)=.11, p=.12$, possibly indicating that the two scales may be measuring different aspects of creativity in this sample. For this reason, they were not combined into a creativity composite score. Instead, these two measures were considered separately in all evaluations of hypotheses involving creativity.

\section{Controlled Oral Word Association Test}

The current study asked the participants to list as many justifications they were able to think of. A measure of verbal fluency was administered to ensure that the participants who produced more justifications were not simply more apt at creating lists. Consequently, there may have arisen a need to control for speed of thought. 
The Controlled Oral Word Association Test (COWAT) (Benton, Hamsher, \& Rey, 1994) is a brief measure of verbal fluency. For this assessment, the participants were asked to list as many words as they could that start with the letters F, A, and then S. Proper nouns, numbers and multiple versions of the same word (i.e. fasted and fasting) do not count. Additionally, the participants were asked to list as many animals and girls' names (or boys' names if male participants) they could think of, as well as creating alternating lists of furniture and fruit, and clothing and sports. Higher numbers indicate higher levels of verbal fluency.

The COWAT was originally developed as verbal fluency test for people suffering from brain injuries. It was oral rather than written (as previous measures had been) to accommodate for those with damage that prevented them from using their writing hand or who suffered from arthritis. It was also designed to be short to improve on previous tests that were seen as tiring and tedious for people who were already in poor physical condition. The COWAT has a coefficient $\alpha$ of .83 and a 6-month test-retest reliability of .74 (Ruff, Light, \& Parker, 1996). In the current study, the coefficient $\alpha$ was .80. In this study, the COWAT did not correlate with any of the elements we measure for this study, and so its use was not necessary for the main analyses.

\section{Balanced Inventory of Desirable Responding}

Because this study is focusing on dishonest behaviors, there was a risk that participants may have felt influenced to respond in certain ways based on perceived social pressure. Therefore, the participants were given the Balanced Inventory of Desirable Responding (BIDR; Paulhus, 1991). The BIDR is the research version of the commercial product known as the Paulhus Deception Scale. It measures two forms of 
desirable responding, Impression Management (IM) and Self-Deceptive Enhancement (SDE). Impression Management is intended to measure a person's tendency to deceive others by deliberately inflating self-descriptions. Self-Deceptive Enhancement is intended to measure inflated self-descriptions that result from unconscious favorable biases rather than conscious deception. For the assessment itself, respondents read 40 statements, and indicate how true that statement was on a 7-point scale ranging from not true to true. For most participants, it takes about 3 to 5 minutes to complete.

The BIDR was developed based on the theory that self-deception consists of two dimensions: the unconscious effort to deny thoughts and feelings that produce psychological conflicts, and a conscious effort to portray oneself in the best light possible. While it is difficult to measure and unconscious bias objectively, the Impression Management scale is highly correlated with lie scales, such as Eysenck's Lie scale, and the MMPI Lie scale, measures of role-playing, such as Wiggins' SD, and Gough's Gi, and the scale is also correlated with agreeableness and conscientiousness scores (Paulhus, 1991). These connections to measures of a person's motivations for social approval, have contributed to its wide use and acceptability as a scale (Li, \& Bagger, 2006). The items were originally developed to reflect these two ideas rationally, and each subsequent version of the measure involved adjustments to the items that reflected the latest empirical studies, conceptual rationales, and practitioner consults.

This measurement of an unconscious bias is difficult, but the BIDR works to come as close as possible. It doesn't ask directly, for example, do you inflate your descriptions of yourself, but rather, it asks participants to answer several questions that most people would not answer yes to, for example, I never cover up my mistakes. A 
person who answers yes to a great deal of these items may have an unconscious positive bias

Internal consistency data for 884 male and female college students were reported with an overall internal consistency $\alpha$ at .83. The $\alpha$ coefficients for Self-Deception ranged from .68 to .80 and from .75 to .86 for Impression Management. (Paulhus, 1988) Testretest correlations for Self-Deceptive Enhancement and Impression Management were .69 and .65 respectively, with a 5-week waiting period between tests (Paulhus, 1988). Concurrent validity was assessed by correlating the test with the Marlowe-Crowne Scale ( $r=.71$; Paulhus, 1988) and the Social Desirability Inventory $(r=.80$; Jacobson, Kellogg, Cauce, \& Slavin, 1977). For this study, the $\alpha$ coefficients for Self-Deception was .66, and was .79 for Impression management. The weak coefficient for SelfDeception is discussed in the limitations secion.

\section{International Personality Item Pool}

The International Personality Item Pool (IPIP) (Goldberg, 1999) is a 50-item personality measure of the Big-Five factor markers of Extraversion, Agreeableness, Conscientiousness, Emotional Stability, and Intellect/Imagination (Goldberg, 1992). For this measure, participants were asked to read statements and indicate how accurate the statement is on a 5-point scale ranging from very inaccurate to very accurate. Examples of items included are "Am the life of the party," "Have a vivid imagination," and "Have excellent ideas."

The IPIP was created in response to the thousands of personality measures developed over 75 years of study. The developers saw that the measures assessing broad personality traits were often copyrighted and rarely tested or improved. They decided to 
produce a public domain personality measure to allow scientists to freely use, assess, and report findings to each other with the goal of improving personality measurement and furthering research in the area. The goal was to create a measure with scales mirroring those in other established measures. They developed 45 initial scales targeting the AB5C scales. The AB5C is a model of the personality domain based on the big five factors of personality (Hofstee, de Raad, \& Goldberg, 1992). Of these, 43 had $\alpha$ coefficients of .70 or higher and 18 with reliabilities at or above .80. Additionally, the IPIP contains 30 constructs similar to the 30 facet scales in the NEO-PI-R (Costa \& McCrae, 2008) with average Cronbach $\alpha$ scores at .80, higher than the NEO scales (.75). The IPIP also has scales designed to mirror the Sixteen Personality Factors Questionnaire, Cloninger's Temperament and Character Inventory, and Gough's California Pathological Inventory, all finding inter item correlations, Cronbach's $\alpha$ scores, and average $\alpha$ scores at or above the original measures themselves (Goldberg, 1999). The internal consistency data from the current study can be seen in Table 2. For this study, the IPIP was used mainly as a distraction task between study activities.

\section{Procedure}

The participants completed a moral justification generation task and a moral justification evaluation task. The tasks were completed in random order. In between tasks, the participants completed the IPIP as a distraction task. This was done to reduce any carryover effects that may have altered the participants' performance on either task based on which one was completed first.

Moral Justification Generation Task: When the participants arrived, they were brought into a room and informed consent was obtained. Next, the participants were 
seated at a computer and read the following short vignette of a person who behaved dishonestly:

A person was walking down a busy street and saw a stranger drop a large wad of cash without noticing. Rather than speaking up, the person quickly grabbed the money off the sidewalk and kept it.

The vignettes used in this study were created because previous studies do not contain vignettes used for the purpose of collecting justifications, as opposed to determining what the participant would do. It is important that the vignettes for this study are gender neutral, involve an act of dishonesty, and are short enough to allow the participant to project his or her own ideas and justifications onto it.

After they read the vignette, the participants clicked "next" and saw the following instructions,

In the space provided below, type out a reason that you think would justify what the person did. There is no need to use full sentences; if it helps you work, you can just write enough so some else can understand. Feel free to write as few or as many justifications as you want. When you've finished, click the button on the bottom of the screen that says "done."

Upon clicking "done," the participants saw a screen instructing them to rate the acceptability of the dishonest behavior using a 5-point scale ranging from extremely unacceptable to extremely acceptable. When the participants finished writing their justifications, they clicked next, and the following vignette immediately appeared on the screen, 
A student lived in a dormitory with one roommate and kept alcohol in the room against university policy. When the RA came by to inspect the room, the person put the alcohol in the roommate's drawer and let the roommate take the punishment.

The participants were then given the same instructions as in the previous task, and they typed their justifications and evaluation of the acceptability of the dishonest behavior.

When the data was collected, it was observed that many participants did in fact type out justifications for the behaviors (e.g., "The person was in desperate need of money," or "The roommate agreed to take the punishment."). Other responses were not justifications, but rather, explanations (e.g., "No morals") or other types of responses (e.g., "There is no justification for this behavior," or "I would go up to the person and ask him or her to return the money to the stranger."). Because the hypotheses were concerned specifically with justifications rather than responses per se, 205 of 925 responses (22\%) were not included in the analyses because they were not justifications. Responses were eliminated only if they clearly represented a non-justification, as in the examples above. The items chosen for elimination were reviewed with the study's committee chair. Even if all responses are included in the analyses, the conclusions of this study are not altered substantively.

Moral Justification Evaluation Task: For the second task, the participants' computer screen displayed this short vignette depicting dishonest behavior, A person was given an exam for a college course. While taking the test, the person noticed that the class assistant dropped the test key on the floor without noticing. The person picked up the key and used it to get $100 \%$ on the test. 
When the participants clicked to the next screen, they were randomly presented with zero, two, four, or eight justifications for the dishonest behavior. The program was loaded with 15 justifications and the ones that appeared on the participants' screens were selected at random. Participants were instructed to assume that the person believes the statements are true. The complete list of justifications was developed to reflect different moral disengagement practices commonly used (Bandura, 1996), and is as follows (the type of moral disengagement is listed in parentheses):

- My grandmother died this last week, and so I did not have time to study (displacement of responsibility/attribution of blame).

- If I did not get an A on this test, I would fail the class and be kicked out of school (displacement of responsibility).

- Last test, I tried to get help from the assistant several times, but the assistant was rude and unhelpful (displacement of responsibility/attribution of blame).

- I have never cheated in school before, and I will never do it again (displacement of responsibility).

- The questions were about obscure facts from the book that are only meant to trick us (displacement of responsibility/attribution of blame).

- I've seen a lot of people cheating in this class before-it's not a big deal (distorting consequences/advantageous comparison).

- I only cheated on a few items...I got most of them right on my own (distorting the consequences/euphemistic language). 
- The professor is a graduate student from another country—half the time I can't understand what the professor is saying (displacement of responsibility/attribution of blame/dehumanization).

- I don't even need this class for my major-I'll never use the information (distorting consequences).

- I have to work a job to pay for my tuition, and it's just been a busy couple of weeks with everything going on (displacement of responsibility/attribution of blame).

- I only cheated on this one test —other people plagiarized their entire final paper (advantageous comparison).

- I was just taking advantage of an opportunity that came my way (euphemistic language).

- It was the assistant's responsibility to keep the key secure, not mine (displacement of responsibility).

- The professor doesn't grade on a curve so it didn't lower anyone else's grade (disregarding consequences).

- With all the assaults and rapes happening around campus, checking a few answers on a test is not that big of a deal (advantageous comparison).

For each of the justifications, the participants indicated how valid the justification is on a 5-point scale ranging from not at all valid to extremely valid. Next, the participants were asked, "How acceptable was this person's behavior?" and they indicated their opinion on a five point scale ranging from extremely unacceptable to extremely acceptable. 


\begin{abstract}
Assessment Tasks
The participants completed the IPIP (Goldberg, 1999) to measure personality, the Creativity Personality Scale, and the Creative Behavior Inventory. The participants also completed the Balanced Inventory of Desirable Responding (Paulhus, 1998) to assess for social desirability, and the COWAT (Benton, Hamsher, \& Rey, 1994) to measure verbal fluency. The CPS and CBI were given after both tasks were completed to prevent any creativity priming that could have taken place if the participants were assessed for creativity beforehand.
\end{abstract}

\title{
Demographics
}

For this study demographic data was collected regarding the participants' age, gender, race, GPA, and SES (see Table 2).

\section{Debriefing}

The participants were debriefed on the research in more detail. They were told that the purpose of the research was to examine connections between creativity and the number/types of justifications given for dishonest behavior. The participants were given the opportunity to ask any questions they may have before they leave. 


\section{CHAPTER IV}

\section{RESULTS}

\section{Descriptive Statistics}

Table 2 provides the means, standard deviations, and Cronbach $\alpha$ coefficients for all measures used, as well as the participants' reported acceptability ratings for both tasks. For task one, an average of the two vignettes was produced.

Table 2

Means, Standard Deviations, and Cronbach $\alpha$ Coefficients for All Measures Used and Acceptability Ratings

\begin{tabular}{lrrc}
\hline Measure & \multicolumn{1}{c}{$M$} & \multicolumn{1}{c}{$S D$} & $\alpha$ \\
\hline Creative Personality Scale & 16.21 & 2.15 & .63 \\
Creative Behavior Inventory & 39.10 & 20.71 & .89 \\
COWAT (z-score) & 0.00 & 1.00 & .80 \\
BIDR Self-Deception & 4.06 & .64 & .66 \\
BIDR Impression Management & 3.74 & .78 & .79 \\
IPIP NEO Extraversion & 2.21 & .82 & .89 \\
IPIP NEO Agreeableness & 3.18 & .47 & .75 \\
IPIP NEO Neuroticism & 2.73 & .64 & .85 \\
IPIP NEO Conscientiousness & 2.14 & .74 & .84 \\
IPIP NEO Openness & 2.60 & .52 & .75 \\
Self-Generated Justifications & 3.48 & 2.45 & \\
Task 1 Acceptability of Dishonesty & .65 & .56 & \\
Task 2 Acceptability of Dishonesty & .75 & .84 & \\
\hline
\end{tabular}

\section{Hypothesis One}

The correlation of the Creative Behavior Inventory and the number of selfgenerated justifications was significant, $r(203)=.16, p=.02$. The correlation of the Creative Personality Scale and the total number of self-generated justifications was not 
significant, $r(203)=-.07, p=.34$. Even where this hypothesis was partially supported, the effect size was small.

\section{Hypothesis Two}

In the first task, the correlation of the total number of self-generated justifications and the average perceived acceptability of dishonest behavior was significant, $r(203)=$ $.14, p=.03$. Although this correlation is consistent with the hypothesis, it should be noted that it is quite small.

In the second task, the correlation of the total number of manipulated justifications given and the average perceived acceptability of the dishonest behavior was not significant, $r(203)=.09, p=.20$. However, as seen in Figure 3, it appears that the relationship between perceived acceptability and the number of evaluated justifications is non-linear. 


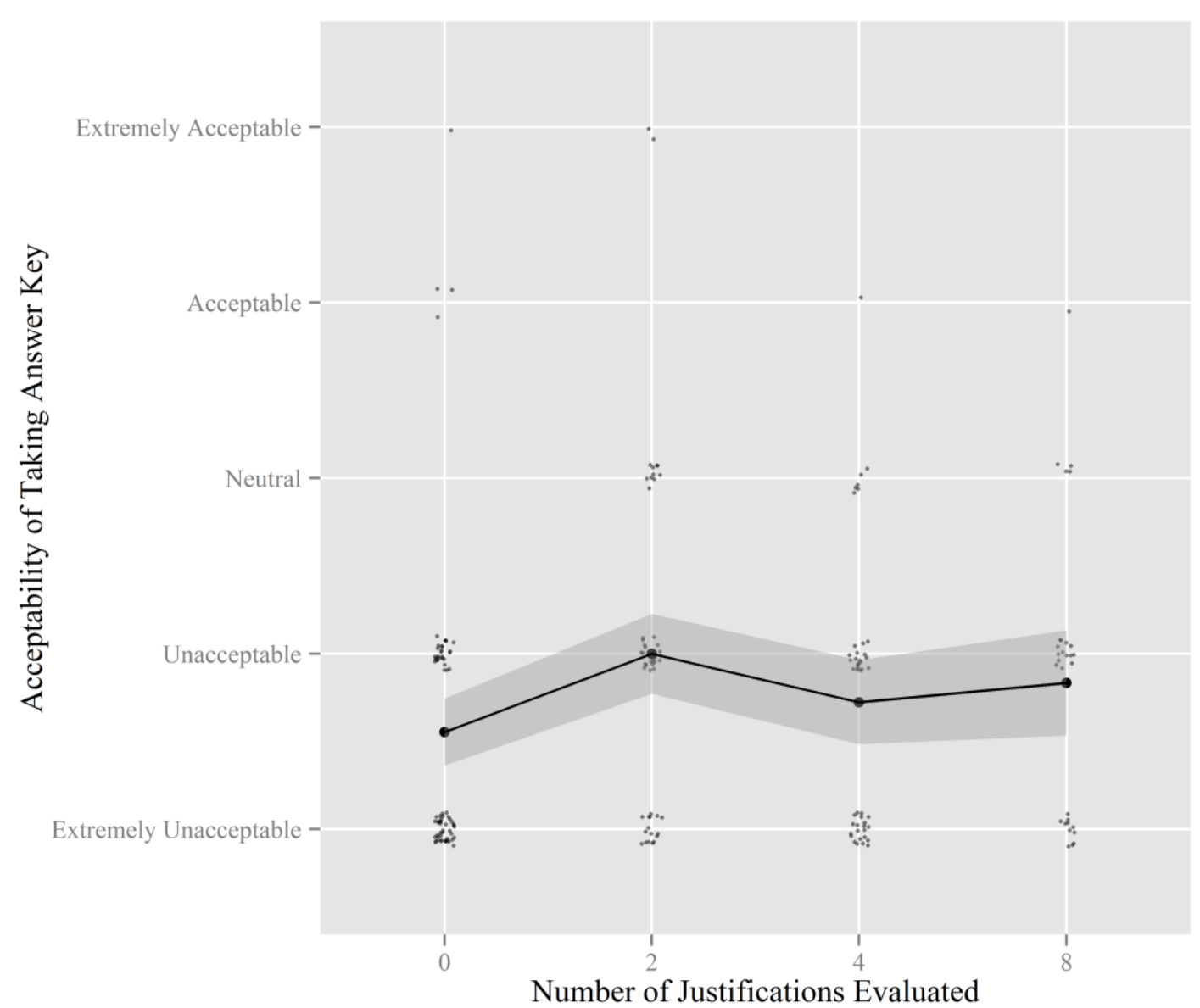

Figure 3. Mean Task 2 Perceived Acceptability Ratings as a Function of the Number of Justifications for Dishonesty.

To test the non-linear effect of justifications in an exploratory follow-up analysis, the predictor was treated as an ordinal variable and the polynomial contrast was evaluated. Because the outcome variable was a single-item Likert scale with five categories, ordered logistic regression was conducted instead of ordinary least squares regression. The polr function from the MASS package (Venables \& Ripley, 2002) was used to compute an ordered logistic regression analysis in the R statistical computing environment (Version 3.2; R Core Team, 2015). In Table 3, the cubic effect of justifications is significant. 
Table 3

Ordered Logistic Regression Coefficients for the Polynomial Effects of Justification Exposure and Evaluation on the Perceived Acceptability of Dishonest Behavior in Task 2

\begin{tabular}{lcccr}
\hline Predictor & $b$ & {$[95 \% \mathrm{CI}]$} & $\sigma_{b}$ & \multicolumn{1}{c}{$t$} \\
\hline Justifications (Linear) & 0.43 & {$[-0.14,1.00]$} & 0.29 & 1.49 \\
Justifications (Quadratic) & -0.44 & {$[-0.99,0.11]$} & 0.28 & -1.55 \\
Justifications (Cubic) & $0.59 *$ & {$[0.06,1.14]$} & 0.27 & 2.16
\end{tabular}

$* p<.05$

In Figure 4, it can be seen that judging the behavior to be extremely unacceptable is most probable when no justifications have been evaluated and that exposure to at least some justifications is associated with less intolerant evaluations. 


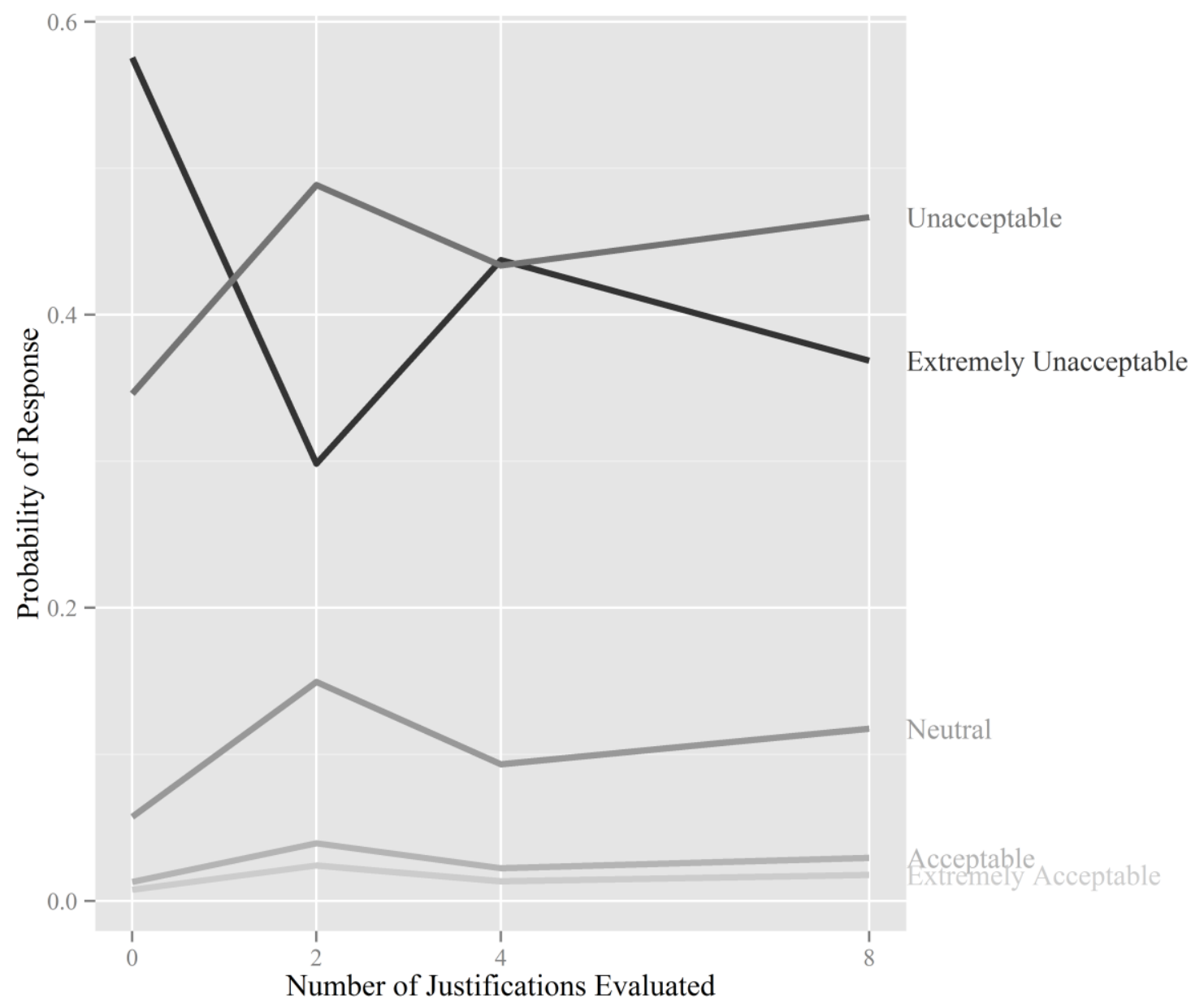

Figure 4. Model-Implied Response Probabilities When Number of Justifications Predicts the Perceived Acceptability of Dishonest Behavior in an Ordered Logistic Regression Model.

To check the robustness of this finding, additional follow-up analyses were conducted in which the number of justifications was treated as a nominal variable. Compared to people who were not exposed to any justifications, people were significantly less likely to evaluate the dishonest behavior as extremely unacceptable when exposed to only two justifications $(b=1.16,95 \% \mathrm{CI}=[0.47,1.86])$ or eight justifications $(b=0.84,95 \% \mathrm{CI}=[0.03,1.66])$. Exposure to four justifications was also associated with a lower probability of harsh evaluation of the behavior $(b=0.55,95 \% \mathrm{CI}$ 
$=[-0.15,1.27])$, but this difference was not statistically significant. If the number of justifications variable is collapsed into two categories (No Justifications vs. Two or More Justifications), the effect still holds $(b=0.86,95 \% \mathrm{CI}=[0.31,1.43])$.

Overall, this hypothesis was only partially and weakly supported. Although exposure to at least some justifications appears to lower the severity of participants' judgments somewhat, as in fewer "extremely unacceptable" responses and more "unacceptable" responses. At four justifications, the two harshest responses met each other, still being the two most likely responses. Therefore, there is no evidence that the effect is cumulative, with additional justifications associated with more tolerance of dishonest behavior.

\section{Hypothesis Three}

As seen in Table 4, neither creativity measure was significantly correlated with perceived acceptability of dishonest behavior in either task. Because there is no observed relationship between creativity and perceived acceptability of dishonest behavior, there is no mediator to identify.

Table 4

Correlations of Creativity and Perceived Acceptability of Dishonest Behavior Acceptability of Dishonest Behavior

\begin{tabular}{llc} 
Measure & Task 1 & Task 2 \\
\hline Creative Behavior Inventory & -.08 & -.05 \\
Creative Personality Scale & -.002 & -.07 \\
\hline
\end{tabular}

Note. None of the correlations are statistically significant.

Despite the null results, the planned mediation analyses were conducted to evaluate the model from Figure 1 as a whole. The results of a path analysis generated from the $\mathrm{R}$ package lavaan (Rosseel, 2012) are presented in Figure 5. In Figure 5, Statistically 
significant standardized paths and correlations are bolded. Although the paths that make up the hypothesized indirect effect from the Creative Behavior Inventory to perceived acceptability of dishonesty via the number of self-generated justifications are both individually statistically significant, the product of the paths (i.e., the indirect effect) is not significant $\left(b=.02, \sigma_{b}=0.01, z=1.47, p=.14\right)$. Furthermore, as is already known from the raw correlation, the total effect of the Creative Behavior Inventory on perceived acceptability of dishonest ratings is not statistically significant $\left(b=.001, \sigma_{b}=0.07, z=\right.$ $0.02, p=.98)$. Thus, this hypothesis was not supported.

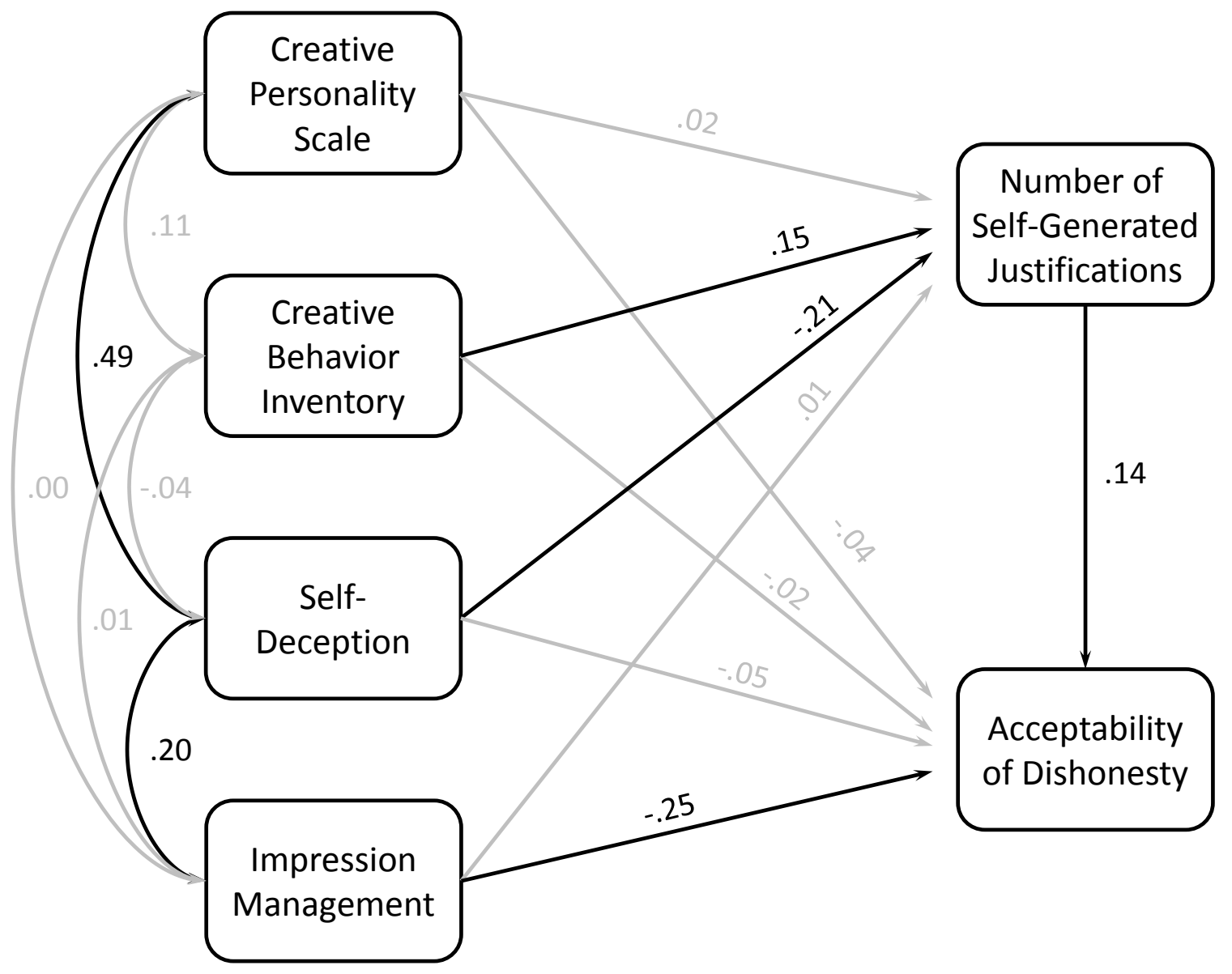

Figure 5. Path Analysis of the Task 1 Variables. 
To evaluate Hypothesis 3 for Task 2 (see Figure 2), an ordered logistic regression was conducted similar to the analyses conducted for Hypothesis 2, with the addition of the two creativity measures and both social desirability measures as covariates. As seen in Table 5, neither creativity measure was a significant predictor of perceived acceptability. However, impression management was associated with less tolerant evaluations of dishonest behavior, as was exposure to at least some justifications (See Figure 6).

Table 5

Ordered Logistic Regression Coefficients in Task 2

\begin{tabular}{lcccr}
\hline Predictor & $b$ & {$[95 \% \mathrm{CI}]$} & $\sigma_{b}$ & \multicolumn{1}{c}{$t$} \\
\hline Justifications (Linear) & 0.34 & {$[-0.24,0.93]$} & 0.30 & 1.16 \\
Justifications (Quadratic) & $-0.58^{*}$ & {$[-1.16,-0.02]$} & 0.29 & -2.01 \\
Justifications (Cubic) & $0.64^{*}$ & {$[0.09,1.20]$} & 0.28 & 2.25 \\
Self-Deception & 0.32 & {$[-0.01,0.66]$} & 0.17 & 1.91 \\
Impression Management & $-0.74^{*}$ & {$[-1.05,-0.43]$} & 0.16 & -4.69 \\
Creative Behavior Inventory & 0.04 & {$[-0.24,0.31]$} & 0.14 & 0.29 \\
Creative Personality Scale & -0.19 & {$[-0.52,0.13]$} & 0.17 & -1.18 \\
\hline
\end{tabular}

$* \mathrm{p}<.05$ 


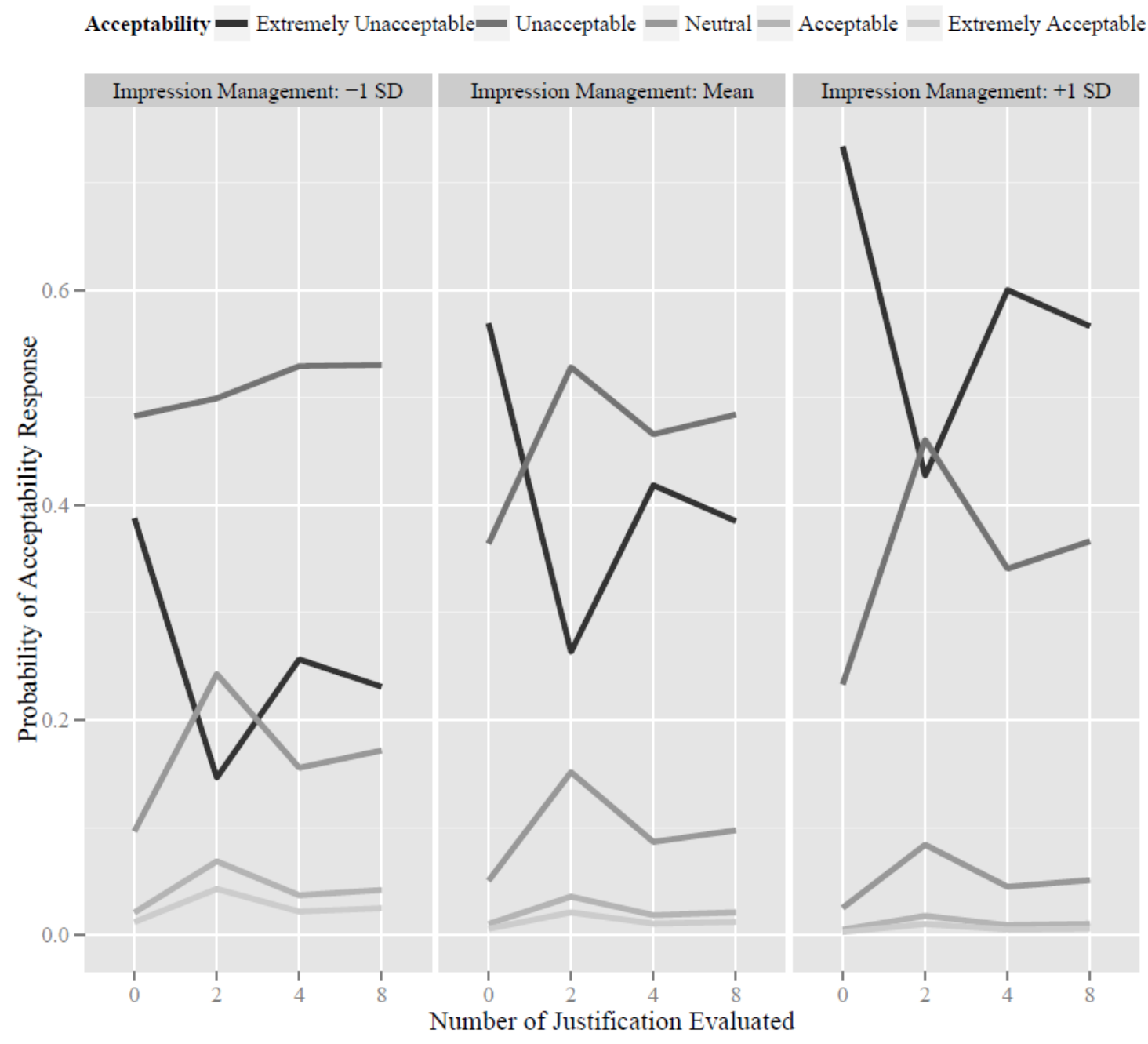

Figure 6. Model-Implied Response Probabilities When Number of Justifications and Impression Management Predicts the Perceived Acceptability of Dishonest Behavior in an Ordered Logistic Regression Model.

\section{Hypothesis Four}

An evaluation of the hypothesized model implied by Figure 1 was conducted in a path analysis. As seen in Table 6, none of the interaction effects were statistically significant. Furthermore the interaction effect model did not significantly improve the model fit over the analogous main effects model in Figure $5, \chi^{2}(4)=5.98, p=.20$. Despite findings that show the connection between Impression Management and the 
perceived acceptability of dishonesty, no moderating relationships were found, leaving this hypothesis as a whole unsupported.

Table 6

Path Analysis of Task 1 Variables with Standardized Variables and Interaction Terms

\begin{tabular}{lccccc}
\hline Outcome $\sim$ Predictor & $b$ & $\sigma_{b}$ & $z$ & $p$ & $95 \%$ CI \\
\hline Justifications $~$ & & & & & \\
Creative Personality Scale & 0.03 & 0.08 & 0.36 & .72 & {$[-0.13,0.19]$} \\
Creative Behavior Inventory & 0.15 & 0.07 & 2.23 & .03 & {$[0.02,0.29]$} \\
Self-Deception & -0.22 & 0.08 & -2.70 & .01 & {$[-0.38,-0.06]$} \\
Impression Management & 0.01 & 0.07 & 0.14 & .89 & {$[-0.13,0.15]$} \\
CPI $\times$ SD & 0.00 & 0.06 & -0.06 & .96 & {$[-0.13,0.12]$} \\
CPI $\times$ IM & 0.02 & 0.07 & 0.32 & .75 & {$[-0.11,0.15]$} \\
CBI $\times$ SD & 0.04 & 0.08 & 0.46 & .65 & {$[-0.12,0.20]$} \\
CBI $\times$ IM & 0.06 & 0.07 & 0.88 & .38 & {$[-0.08,0.21]$}
\end{tabular}

Acceptability

$\begin{array}{lrrrrc}\text { Justifications } & 0.14 & 0.07 & 1.96 & .05 & {[0.00,0.27]} \\ \text { Creative Personality Scale } & -0.04 & 0.08 & -0.54 & .59 & {[-0.19,0.11]} \\ \text { Creative Behavior Inventory } & -0.02 & 0.07 & -0.28 & .78 & {[-0.15,0.12]} \\ \text { Self-Deception } & -0.05 & 0.08 & -0.58 & .56 & {[-0.20,0.11]} \\ \text { Impression Management } & -0.25 & 0.07 & -3.64 & .00 & {[-0.39,-0.12]}\end{array}$

Note. $\mathrm{CPI}=$ Creative Personality Scale, $\mathrm{CBI}=$ Creative Behavior Inventory, $\mathrm{SD}=$ SelfDeception, IM = Impression Management 


\section{CHAPTER V \\ DISCUSSION}

\section{Conclusions}

\section{Hypothesis One}

The first task asked the participants to produce their own justifications for dishonest behavior, and it was found that those who scored high in the Creative Behavior Inventory were able to produce more justifications overall, supporting the conclusions of previous research (Gino \& Ariely, 2012), but not those who scored high on the Creative Personality Scale. Thus the hypothesis that creative people are able to generate justifications for dishonesty quickly is only partially and weakly supported.

For this study, the two measures of creativity did not correlate with each other, and this result may speak to the wide variety of ways that creativity can be measured (i.e., self-reported personality traits and self-reported creative productivity). A follow-up study would be required to explain why one measure of creativity was correlated with number of justifications generated while the other was not. One possibility may be that the Creative Behavior Inventory measured reports of actual participant activities and experience, and creating justifications was a creative performance task as well. Those who scored high on the Creative Personality Scale simply viewed themselves as creative, whereas those who scored high in the Creative Behavior Inventory had actually 
completed creative activities. However, previous research has found that global measures of attitude do not accurately predict specific behaviors, with correlations rarely reaching higher than .40 (Ajzen \& Fishbein 1977; Kraus, 1995; McGuire, 1985; Wicker, 1969), and so this connection may or may not explain the findings.

It is important to note that the Creative Behavior Inventory had an $\alpha$ coefficient of .89 and produced a significant correlation with number of justifications, while the Creative Personality Scale did not and only had an $\alpha$ coefficient of .63. The low reliability of the Creative Personality Scale may be contributing to the non-significant findings.

\section{Hypothesis Two}

In the first task, the total number of justifications produced was correlated with the average perceived acceptability of dishonest behavior. It is this element that has been implied previously (Gino \& Ariely, 2012), but was not directly measured. While the finding was significant, it is important to point out two ideas. First, the effect size was small. Second, despite this effect, the average perceived acceptability of the behavior was still between extremely unacceptable and unacceptable. Nevertheless, even small effects, when aggregated over a lifetime can add up to large differences in life outcomes (Barrick \& Mount, 2005).

In the second task, the number of justifications provided was not significantly correlated with the perceived acceptability of the dishonest behavior. However, further investigation found a non-linear relationship. Specifically, the number of "extremely unacceptable responses" was lowered, and the number of "unacceptable" responses increased when exposed to justifications. Overall, the behavior is still seen as less widely 
extremely unacceptable, but more broadly unacceptable. These findings may suggest that the justifications provided opportunities for the participants to morally disengage from what may otherwise be extremely harsh evaluations of the behavior (Bandura, 1991).

It is most likely that a person will view a dishonest behavior as extremely unacceptable when no justifications have been evaluated and that exposure to at least some justifications is associated with less intolerant evaluations. With two justifications, participants were more likely to still perceive the behavior as unacceptable, just not extremely unacceptable. Although exposure to at least some justifications appears to lower the severity of participants' judgments somewhat, there is no evidence that the effect is cumulative, with additional justifications associated with less intolerance of dishonest behavior.

The action of reading a person's justifications may allow the participant to consider the mind of and identify with the person acting dishonestly (Pizarro et al, 2006; Young \& Waytz, 2012), allowing them to identify with the person and their decision to morally disengage (Bandura, 1991).

\section{Hypothesis Three}

This study was unable to find any significant connection between creativity and perceived acceptability of dishonest behavior whether the participants were presented with justifications or asked to produce their own. Despite this, different indirect paths that one could go from creativity to perceived acceptability of dishonesty were investigated. In the first task, a significant path was found from the Creative Behavior Inventory to the number of self-generated justifications, and then another significant path was found from the number of self-generated justifications to perceived acceptability of dishonesty. 
However, the hypothesized indirect effect was not large enough to be statistically significant.

\section{Hypothesis Four}

While a significant relationship was found between scores on the Creative Behavior Inventory and the number of self-generated justifications, no other significant relationships or moderating relationships were found. It is difficult to draw conclusions on why this may be so without additional follow-up studies. Additionally, several negative correlations were found between perceived acceptability of dishonesty and measures of social desirability.

During the process of investigating the model, it was found that impression management was associated with less tolerant evaluations of dishonest behavior, and as previously reported in Hypothesis 2, exposure to at least some justifications was associated with evaluating dishonest behavior less harshly.

Impression management was associated with less tolerant evaluations of dishonest behavior. When impression management was low, there were more "unacceptable" evaluations, than "extremely unacceptable" evaluations, but when Impression Management was high, there were more "extremely unacceptable" evaluations than "unacceptable" evaluations. When people are concerned with out they appear to others, they are more likely to view dishonest behaviors extremely harshly. This coincides with research that explains how one's desire to be viewed as a moral person affect one's choices of behavior, as well as how one believes they will be viewed by others (Mead, Baumeister, Gino, Schweitzer, \& Ariely, 2009). However, because these relationships 
were not of direct focus in the study and no moderating relationships were found, this hypothesis as a whole is unsupported.

\section{Limitations and Future Directions}

This study had some limitations that should be acknowledged. First, the participants were asked to produce justifications and perceived acceptability ratings on the dishonest behaviors of others. In previous studies, the participants were put into situations where they were dishonest for their own personal gain, rather than given the opportunity to consider the dishonesty of another. Future studies should allow the participants to personally gain from dishonesty while measuring number of justifications. It is possible that since the participants were not asked to justify their own lies, they were more likely to align their motivating emotions towards justifying a moral stance against dishonesty, as seen in several studies (Haidt, 2001, 2012; Haidt et al., 1993), rather than justifying the dishonesty. Perhaps it is not simply that creative people are more dishonest in general, but that they are more dishonest when properly motivated to be so, and such motivation may produce more robust findings. This leads to an additional research question of "How does personal motivation affect one's view of dishonesty?"

Additionally, three items from the Creative Personality Scale were unintentionally omitted (clever, snobbish, and unconventional). The scale used in the current study was a simple sum of the 27 remaining items (after reverse scoring the negatively keyed items). In this study, the $\alpha$ coefficient for this scale was 0.63 . Had the three omitted items been included, the Spearman-Brown Prophecy formula estimates that the reliability coefficient might have been a little higher $(\alpha=.65)$, assuming that the omitted items were equally good indicators as the 27 items that were included. Even at 0.65 , this is only marginally 
acceptable. Achieving higher reliability with this measure may have resulted in a higher correlation with the Creative Behavior Inventory, and the low reliability observed for this measure may be contributing to the non-significant results. In a similar fashion, the low reliability of the Self-Deception Scale of the BIDR observed in this sample may have attenuated its predictive validity.

Third, a programming error resulted in the omission of the single-justification condition in Task 2 . The intended manipulation was $0,1,2,4$, and 8 justifications instead of $0,2,4$, and 8 justifications. Though regrettable, this error is unlikely to have altered the results substantially. Even if there is something fundamentally different about the experience of reading a single justification instead of multiple justifications, the original hypothesis that exposure to multiple justifications has a cumulative effect on one's tolerance of dishonesty would not have been supported.

For this study, the majority of participants were between the ages of 18 and 20. At this stage, many are only beginning to live independently, and their list of creative achievements may include activities that their schools and/or families required/encouraged. Additionally, their influences on self-view may still be heavily reliant on their parents. Personality is impacted by a number of factors, including environment (Roberts, Wood, \& Caspi, 2010). Some related research questions may be:

- How do people of different age groups view dishonesty?

- What role does creativity play in a person's view of dishonesty over the lifespan?

- Are children more likely to justify their dishonest behavior?

- How does creativity manifest itself in middle aged versus young adults? 
Finally, in Task 1, the participants were asked to generate justifications for dishonest behavior. Of the 925 responses, 205 of them were not justifications. This may have been due to the style of administration. The participants completed the task on a computer, with directions read aloud to them over the computer, and were asked to type their responses. Perhaps if task one was given with a human reading the directions and recording their responses, the directions could be further clarified, cutting down on the number of non-justification responses.

Additionally, the existence of these non-justifications bring up additional opportunities for study. Perhaps some of the participants were exhibiting moral indignation at an authority asking them to justify dishonesty, leading to questions of authority and morality as famously studied (Milgram, 1963). Some of the nonjustifications involved a participant essentially thinking out loud, and these responses may inspire future studies into how personal narratives effect the way people view themselves and their role as moral agents.

Overall, when it comes to creativity and honesty, the relationship appears to be complicated. A person's feelings and thoughts about right and wrong interact with each other, and motivations seems to play an important role in how people view dishonesty. This study found mixed results for whether creative people can produce more justifications, and this may be due to what element of creativity is being measured, motivation, or other factors. Justifications do seem related to perceived acceptability of dishonesty, but again, this relationship is complicated, depending on who is lying, who is producing justifications, and other possible factors. Finally, this study was unable to find any significant connection between creativity and perceived acceptability of dishonest 
behavior, contrary to previous studies. In the end, what's left are more questions than answers, and rich possibilities for future investigations. 


\section{REFERENCES}

Ajzen, I., \& Fishbein, M. (1977). Attitude-behavior relations: A theoretical analysis and review of empirical research. Psychological Bulletin, 84, 888-918. doi:10.1037/0033-2909.84.5.888.

Amabile, T. M. (1988). A model of creativity and innovation in organizations. In B. Staw and L. Cummings, (Eds.), Research in Organizational Behavior, 22 (pp. 123167). New York: Elsevier.

Amabile, T. M., Conti, R., Coon, H., Lazenby, J., \& Herron, M. (1996). Assessing the work environment for creativity. Academy of Management Journal, 39(5), 1154 1184. doi:10.2307/256995.

Andrus, B. (1969). The infamous of Nuremberg. London: Frewin.

Ayal, S., \& Gino, F. (2012). Honest rationales for dishonest behavior. In M. Mikulincer, P. R. Shaver, M. Mikulincer, \& P. R. Shaver (Eds.), The social psychology of morality: Exploring the causes of good and evil (pp. 149-166). Washington, DC: American Psychological Association.

Baer, M., \& Oldham, G. R. (2006). The curvilinear relation between experienced creative time pressure and creativity: moderating effects of openness to experience and support for creativity. Journal of Applied Psychology, 91(4), 963-970. doi:10.1037/0021-9010.91.4.963.

Bandura, A. (1991). Social cognitive theory of moral thought and action. In W. Kurtines, M. Gewirtz, \& L. Jacob (Eds.), Handbook of moral behavior and development (pp. 45-103). Hillsdale, NJ: L. Erlbaum.

Bandura, A. (1999). Moral disengagement in the perpetration of inhumanities. Personality and Social Psychology Review, 3(3), 193-209. doi:10.1207/s15327957pspr0303_3.

Bandura, A., Barbaranelli, C., Caprara, G. V., \& Pastorelli, C. (1996). Mechanisms of moral disengagement in the exercise of moral agency. Journal of Personality and Social Psychology, 71(2), 364-374. doi:10.1037/0022-3514.71.2.364.

Bandura, A., Underwood, B., \& Fromson, M. E. (1975). Disinhibition of aggression through diffusion of responsibility and dehumanization of victims. Journal of 
Research in Personality, 9(4), 253-269. doi:10.1016/0092-6566(75)90001-X. Barrick, M. R. \& Mount, M. K. (2005). Yes, personality matters: Moving on to more important matters. Human Performance, 18(4), 359-372.

Barron, F. (1955). The disposition toward originality. The Journal of Abnormal and Social Psychology, 51(3), 478-485. doi:10.1037/h0048073.

Bastian, B., Laham, S. M., Wilson, S., Haslam, N., \& Koval, P. (2011). Blaming, praising, and protecting our humanity: The implications of everyday dehumanization for judgments of moral status. British Journal of Social Psychology, 50(3), 469-483. doi:10.1348/014466610X521383.

Beaussart, M. L., Andrews, C. J., \& Kaufman, J. C. (2013). Creative liars: The relationship between creativity and integrity. Thinking Skills and Creativity, 9, 129-134. doi:10.1016/j.tsc.2012.10.003.

Benton, A., Hamsher, K., \& Rey, G. J. (1994). Multilingual Aphasia Examination. Iowa City: AJA Associates.

Bolinger, D., \& Jones, G. R. (1980). Language, the loaded weapon: The use and abuse of language today. New York: Longman.

Cikara, M., Eberhardt, J. L., \& Fiske, S. T. (2011). From agents to objects: Sexist attitudes and neural responses to sexualized targets. Journal of Cognitive Neuroscience, 23(3), 540-551. doi:10.1162/jocn.2010.21497.

Cohen, J., Cohen, P., West, S. G., \& Aiken, L. S. (2003). Applied multiple regression/correlation analysis for the behavioral sciences. Mahwah, NJ: Lawrence Erlbaum Associates.

Costa, P. T., \& McCrae, R. R. (2008). The Revised NEO Personality Inventory (NEO-PIR). In G. Boyle, G. Matthews, \& D.H. Sklofske (Eds.), The SAGE handbook of personality theory and assessment, (Volume 2, pp. 179-198). Thousand Oaks, CA: Sage.

Diener, E. (1977). Deindividuation: Causes and consequences. Social Behavior and Personality: An International Journal, 5(1), 143-155. doi:10.2224/sbp.1977.5.1.143.

Diener, E., Dineen, J., Endresen, K., Beaman, A. L., \& Fraser, S. C. (1975). Effects of altered responsibility, cognitive set, and modeling on physical aggression and deindividuation. Journal of Personality and Social Psychology, 31(2), 328-337. doi: /10.1037/h0076279. 
Dollinger, S., Urban, K., \& James, T. (2004). Creativity and openness: Further validation of two creative product measures. Creativity Research Journal, 16(1), 35-47. doi:10.1207/s15326934crj1601_4.

Duster, T., (1971). Conditions for guilt-free massacre. In N. Sanford \& C. Comstock (Eds.), Sanctions for evil (pp. 25-36). Boston: Beacon.

Feist, G. J. (1998). A meta-analysis of personality in scientific and artistic creativity. Personality and Social Psychology Review, (2nd ed.; pp 290-309). doi:10.1207/s15327957pspr0204_5.

Gaudine, A., \& Thorne, L. (2001). Emotion and ethical decision-making in organizations. Journal of Business Ethics, 31(2), 175-187.

Getzels, J. W., \& Jackson, P. W. (1962). Creativity and intelligence: Explorations with gifted students. New York: Wiley.

Gino, F., \& Ariely, D. (2012). The dark side of creativity: Original thinkers can be more dishonest. Journal of Personality and Social Psychology, 102(3), 445-459. doi:10.1037/a0026406.

Gino, F., Ayal, S., \& Ariely, D. (2009). Contagion and differentiation in unethical behavior: The effect of one bad apple on the barrel. Psychological Science, 20(3), 393-398. doi:10.1111/j.1467-9280.2009.02306.x.

Gino, F., \& Wiltermuth, S. (2014). Evil genius? How dishonesty can lead to greater creativity. Psychological Science, 25(4), 973-981. doi:10.1177/0956797614520714.

Goldberg, L. R. (1992). The development of markers for the Big-Five factor structure. Psychological Assessment, 4(1), 26-42.

Gough, H. G. (1979). A creative personality scale for the Adjective Check List. Journal of Personality and Social Psychology, 37(8), 1398-1405.

Gray, K., \& Wegner, D. M. (2009). Moral typecasting: divergent perceptions of moral agents and moral patients. Journal of Personality and Social Psychology, 96(3), 505-520. doi:10.1037/a0013748.

Gray, K., Young, L., \& Waytz, A. (2012). Mind perception is the essence of morality. Psychological Inquiry, 23(2), 101-124. doi:10.1080/1047840X.2012.651387.

Gruenfeld, D. H., Inesi, M. E., Magee, J. C., \& Galinsky, A. D. (2008). Power and the objectification of social targets. Journal of Personality and Social Psychology, 95(1), 111-127. doi: 10.1037/0022-3514.95.1.111. 
Guilford, J. P. (1975). Creativity: A quarter century of progress. In I. A. Taylor \& J. W. Getzels (Eds.), Perspectives in creativity (pp. 37-59). Chicago: Aldine.

Haidt, J. (2001). The emotional dog and its rational tail: A social intuitionist approach to moral judgment. Psychological Review, 108(4), 814-834. doi:10.1037/0033295X.108.4.814.

Haidt, J. (2012). The righteous mind: Why good people are divided by politics and religion. New York: Pantheon Books.

Haidt, J., Koller, S. H., \& Dias, M. G. (1993). Affect, culture, and morality, or is it wrong to eat your dog? Journal of Personality and Social Psychology, 65(4), 613-628.

Haney, C., Banks, C., \& Zimbardo, P. (2004). A Study of Prisoners and Guards in a Simulated Prison. In M. Balfour (Ed.), Theatre in prison (pp. 19-33). Portland, OR: Intellect Ltd.

Harris, L. T., \& Fiske, S. T. (2011). Dehumanized perception: A psychological means to facilitate atrocities, torture, and genocide? Zeitschrift Für Psychologie/Journal of Psychology, 219(3), 175-181. doi:10.1027/2151-2604/a000065.

Hauser, M . D . 2006 : Moral Minds: How Nature Designed Our Universal Sense of Right and Wrong. New York : Ecco/Harper Collins.

Hauser, M., Cushman, F., Young, L., Kang-Xing Jin, R., \& Mikhail, J. (2007). A Dissociation Between Moral Judgments and Justifications. Mind and language, 22(1), 1-21. doi:10.1111/j.1468-0017.2006.00297.x

Hocevar, D. (1980). Intelligence, divergent thinking, and creativity. Intelligence, 4(1), 25-40. doi:10.1016/0160-2896(80)90004-5.

Hofstee, W.K., De Raand, B., \& Goldberg, L.R. (1992). Integration of the big five and circumplex approaches to trait structure. Journal of personality and social psychology, 63(1), 146-163. doi:10.1037/0022-3514.63.1.146.

Jacobson, L. I., Kellogg, R. W., Cauce, A. M., \& Slavin, R. S. (1977). A multidimensional social desirability inventory. Bulletin of the Psychonomic Society, 9(2), 109-110.

Keen, S. (1986). Faces of the enemy: Reflections of the hostile imagination. San Francisco: Harper \& Row.

Kelman, H. C. (1973). Violence without moral restraint: Reflections on the dehumanization of victims and victimizers. Journal of Social Issues, 29(4), 2561 . 
Kelman, H. C., \& Hamilton, V. L. (1989). Crimes of obedience: Toward a social psychology of authority and responsibility. New Haven, CT: Yale University Press.

Kohlberg, L., \& Hersh, R. H. (1977). Moral development: A review of the theory. Theory into Practice, 16(2), 53-59.

Kramer, M. (1990). The moral logic of Hizballah. In W. Reich (Ed.), Origins of terrorism: Psychologies, ideologies, theologies, states of mind (pp. 131-157). Washington, DC: Woodrow Wilson Center Press.

Krathwohl, D. R. (2002). A revision of Bloom's taxonomy: An overview. Theory into practice, 41(4), 212-218.

Kraus, S. J. (1995). Attitudes and the prediction of behavior: A meta-analysis of the empirical literature. Personality and Social Psychology Bulletin, 21(1), 58-75. doi:10.1177/0146167295211007.

Kunda, Z. (1990). The case for motivated reasoning. Psychological Bulletin, 108(3), 480-498.

Li, A., \& Bagger, J. (2006). Using the BIDR to distinguish the effects of impression management and self-deception on the criterion validity of personality measures: A meta-analysis. International Journal of Selection and Assessment, 14(2), 131141.

Lutz, W. D. (1987). Language, appearance and reality: Doublespeak in 1984. ETC: A Review of General Semantics, 44(4), 382-91.

Margolis, H. (1987). Patterns, thinking, and cognition: A theory of judgment. Chicago: University of Chicago Press.

McGuire, W.J. (1985). Attitudes and attitude change. In G. Lindzey \& E. Aronson (Eds.), Handbook of social psychology ( $3^{\text {rd }}$ ed., Vol. 2, pp. 233-346). New York: Random House.

Mead, N. L., Baumeister, R. F., Gino, F., Schweitzer, M. E., \& Ariely, D. (2009). Too tired to tell the truth: Self-control resource depletion and dishonesty. Journal of Experimental Social Psychology, 45(3), 594-597. doi:10.1016/j.jesp.2009.02.004.

Milgram, S. (1963). Behavioral study of obedience. The Journal of Abnormal and Social Psychology, 67(4), 371-378.

Milgram, S. (1974) Obedience to authority: An experimental view. New York: Harper \& Row. 
Miller, W. I. (1998). The anatomy of disgust. Cambridge, MA: Harvard University Press.

Mumford, M., \& Gustafson, S. (1988). Creativity syndrome: Integration, application, and innovation. Psychological Bulletin, 103(1), 27-43.

Paulhus, D. (1988). Assessing self-deception and impression management in self-reports: The balanced inventory of desirable responding. (Manual available from the author at the Department of Psychology, University of British Columbia, Vancouver, B.C., Canada (V6T, 1Y7).

Paulhus, D. (1991). Measurement and control of response bias. In J. Robinson, P. Shaver, \& L. Wrightsman (Eds.), Measures of personality and social psychological attitudes (pp. 17-59). New York: Academic Press.

Pizarro, D. (2000). Nothing more than feelings? The role of emotions in moral judgment. Journal for the Theory of Social Behaviour, 30(4), 355-375.

Pizarro, D. A., Detweiler-Bedell, B., \& Bloom, P. (2006). The creativity of everyday moral reasoning. In J. Kaufman \& J. Baer (Eds.), Creativity and reason in cognitive development (pp. 81-98). New York: Cambridge University Press.

Preacher, K. J., \& Hayes, A. F. (2008). Asymptotic and resampling strategies for assessing and comparing indirect effects in multiple mediator models. Behavior Research Methods, 40(3), 879-891. doi: 10.3758/BRM.40.3.879.

R Core Team (2015). R: A language and environment for statistical computing [computer software]. Retrieved from https://www.R-project.org.

Rapoport, D. C., \& Alexander, Y. (Eds.). (1989). The morality of terrorism: Religious and secular justifications. New York: Columbia University Press.

Reich, W. (Ed.). (1998). Origins of terrorism: Psychologies, ideologies, theologies, states of mind. Washington, DC: Woodrow Wilson Center Press.

Rende, B. (2000). Cognitive flexibility: Theory, assessment, and treatment. Seminars In Speech \& Language, 21(2), 121-132.

Roberts, B. W., Wood, D., \& Caspi, A. (2010). The development of personality traits in adulthood. In O. P. John, R. W. Robins, \& L. A. Pervi (Eds.), Handbook of personality: Theory and research (3rd ed., pp. 375-398). New York: Guilford.

Rosseel, Y. (2012). Lavaan: An R Package for Structural Equation Modeling. Journal of Statistical Software, 48(2), 1-36. 
Rozin, P., Haidt, J., \& McCauley, C.R. (2000). Disgust. In M. Lewis \& J. Haviland-Jones (Eds.), Handbook of emotions (2nd ed.; pp, 637-653). New York: Guilford.

Ruff, R., Light, R, Parker, S., \& Levin, S. (1996). Benton Controlled Oral Word Association Test: Reliability and updated norms. Archives of Clinical Neuropsychology, 11(4), 329-338. doi:10.1016/0887-6177(95)00033-X.

Runco, M. A. (2004). Creativity. Annual Review of Psychology, 55, 657-687. doi:10.1146/annurev.psych.55.090902.141502.

Runco, M. A., \& Jaeger, G. J. (2012). The standard definition of creativity. Creativity Research Journal, 24(1), 92-96. doi:10.1080/10400419.2012.650092.

Schaefer, C. E. (1972). Follow-up study of a creativity scale for the Adjective Check List. Psychological Reports, 30(2), 662.

Schaefer, C. E. (1973). A five-year follow-up study of the self-concept of creative adolescents. Journal of Genetic Psychology, 123(1), 163-170. doi:10.1080/00221325.1973.10533200.

Schweitzer, M. E., \& Hsee, C. K. (2002). Stretching the truth: Elastic justification and motivated communication of uncertain information. Journal of Risk and Uncertainty, 25(2), 185-201.

Shalley, C. E., Zhou, J., \& Oldham, G. R. (2004). The Effects of Personal and Contextual Characteristics on Creativity: Where Should We Go from Here? Journal of management, 30(6), 933-958. doi:10.1016/j.jm.2004.06.007.

Shalvi, S., Handgraaf, M. J., \& De Dreu, C. K. (2011). Ethical manoeuvring: Why people avoid both major and minor lies. British Journal of Management, 22(1), 16-27. doi: 10.1111/j.1467-8551.2010.00709.x.

Silvia, P. J. (2008). Creativity and intelligence revisited: A latent variable analysis of Wallach and Kogan (1965). Creativity Research Journal, 20(1), 34-39. doi:10.1080/10400410701841807.

Silvia, P. J., Wigert, B., Reiter-Palmon, R., \& Kaufman, J. C. (2012). Assessing creativity with self-report scales: A review and empirical evaluation. Psychology of Aesthetics, Creativity, and the Arts, 6(1), 19-34. doi:10.1037/a0024071.

Simonton, D. K. (2003). Scientific creativity as constrained stochastic behavior: The integration of product, person, and process perspectives. Psychological Bulletin, 129(4), 475-494. doi:10.1037/0033-2909.129.4.475. 
Smelser, N. J. (1971). Some determinants of destructive behavior. In W. E. Henry \& N. Sanford (Eds.), Sanctions for evil (pp. 15-25). San Francisco, CA: Jossey-Bass.

Smith, J. M., \& Schaefer, C. E. (1969). Development of a creativity scale for the Adjective Check List. Psychological Reports, 25(1), 87-92.

Snyder, M. L., Kleck, R. E., Strenta, A., \& Mentzer, S. J. (1979). Avoidance of the handicapped: An attributional ambiguity analysis. Journal of Personality and Social Psychology, 37(12), 2297-2306.

Spiro, R. J., \& Jehng, J. C. (1990). Cognitive flexibility and hypertext: Theory and technology for the nonlinear and multidimensional traversal of complex subject matter. In D. Nix \& R. Spiro (Eds.), Cognition, education, and multimedia: Exploring ideas in high technology (pp. 162-205). Hillsdale, NJ: Erlbaum.

Sternberg, R. J. (Ed.). (1999). Handbook of creativity. New York: Cambridge University Press.

Tilker, H. A. (1970). Socially responsible behavior as a function of observer responsibility and victim feedback. Journal of Personality and Social Psychology, 14(2), 95-100. doi:10.1037/h0028773.

Torrance, E. P. (1959). Current research on the nature of creative talent. Journal Of Counseling Psychology, 6(4), 309-316. doi:10.1037/h0042285.

Venables, W. N., \& Ripley, B. D. (2002) Modern applied statistics with $S$ (4 ${ }^{\text {th }}$ ed.). New York: Springer.

Wallach, M. A., \& Kogan, N. (1965). The roles of information, discussion, and consensus in group risk taking. Journal of Experimental Social Psychology, 1(1), 1-19.

Ward, J., Thompson-Lake, D., Ely, R., \& Kaminski, F. (2008). Synaesthesia, creativity and art: What is the link? British Journal Of Psychology, 99(1), 127-141. doi:10.1348/000712607X204164.

Wicker, A. W. (1969). Attitudes versus actions: The relationship of verbal and overt behavioral responses to attitude objects. Journal of Social Issues, 25(4), 41-78. 


\section{APPENDIX A}

\section{QUESTIONNAIRES}

Demographics Form

1. Age:

2. Gender:

3. Ethnicity:

4. Year in School:

5. College Major:

6. Approximate ISU GPA:

7. Sexual Orientation:

8. Mother's Highest Educational Level:

9. Father's Highest Educational Level:

10. Mother's Approximate Income:

11. Father's Approximate Income:

12. Creativity Personality Scale

Instructions: Read the following list of adjectives. Circle the ones that you think best describe you.

1. affected

2. capable

3. cautious

4. commonplace

5. confident

6. conservative

7. conventional

8. dissatisfied

9. egotistical

10. honest

11. humorous

12. individualistic

13. informal

14. insightful

15. intelligent

16. interests narrow

17. interests wide 
18. inventive

19. mannerly

20. original

21. reflective

22. resourceful

23. self-confident

24. sexy

25. sincere

26. submissive

27. suspicious

\section{Controlled Oral Word Association}

Given one minute for each, write as many words as you can think of that begin with the following

letters:

F, A, S

Categories:

Animals, names, furniture/fruit, clothing/sports

\section{International Personality Item Pool}

How Accurately Can You Describe Yourself?

Describe yourself as you generally are now, not as you wish to be in the future. Describe yourself as you honestly see yourself, in relation to other people you know of the same sex as you are, and roughly your same age. So that you can describe yourself in an honest manner, your responses will be kept in absolute confidence. Indicate for each statement whether it is Very Inaccurate, Moderately Inaccurate, Neither Accurate Nor Inaccurate, Moderately Accurate, or Very Accurate as a description of you.

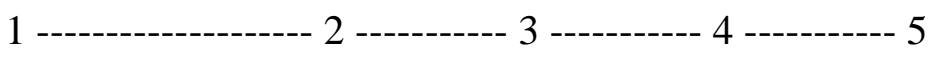

Very Inaccurate Neither Very Accurate

1. Am the life of the party.

2. Feel little concern for others.

3. Am always prepared.

4. Get stressed out easily.

5. Have a rich vocabulary.

6. Don't talk a lot.

7. Am interested in people.

8. Leave my belongings around. 
9. Am relaxed most of the time.

10. Have difficulty understanding abstract ideas.

11. Feel comfortable around people.

12. Insult people.

13. Pay attention to details.

14. Worry about things.

15. Have a vivid imagination.

16. Keep in the background.

17. Sympathize with others' feelings.

18. Make a mess of things.

19. Seldom feel blue.

20. Am not interested in abstract ideas.

21. Start conversations

22. Am not interested in other people's problems.

23. Get chores done right away.

24. Am easily disturbed.

25. Have excellent ideas.

26. Have little to say.

27. Have a soft heart.

28. Often forget to put things back in their proper place.

29. Get upset easily.

30. Do not have a good imagination

31. Talk to a lot of different people at parties.

32. Am not really interested in others.

33. Like order.

34. Change my mood a lot.

35. Am quick to understand things.

36. Don't like to draw attention to myself.

37. Take time out for others.

38. Shirk my duties.

39. Have frequent mood swings.

40. Use difficult words.

41. Don't mind being the center of attention.

42. Feel others' emotions.

43. Follow a schedule.

44. Get irritated easily.

45. Spend time reflecting on things.

46. Am quiet around strangers.

47. Make people feel at ease.

48. Am exacting in my work.

49. Often feel blue.

50. Am full of ideas. 


\section{Balanced Inventory of Desirable Responding}

Using the scale below as a guide, write a number beside each statement to indicate how much you agree with it.

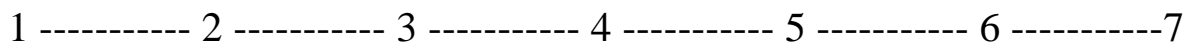
Not True
Somewhat True
Very True

1. My first impressions of people usually turn out to be right.

2. It would be hard for me to break any of my bad habits.

3. I don't care to know what other people really think of me.

4. I have not always been honest with myself

5. I always know why I like things.

6. When my emotions are aroused, it biases my thinking.

7. Once I've made up my mind, other people can seldom change my opinion.

8. I am not a safe driver when I exceed the speed limit.

9. I am fully in control of my own fate.

10. It's hard for me to shut off a disturbing thought.

11. I never regret my decisions.

12. I sometimes lose out on things because I can't make up my mind soon enough.

13. The reason I vote is because my vote can make a difference.

14. My parents were not always fair when they punished me.

15. I am a completely rational person.

16. I rarely appreciate criticism.

17. I am very confident of my judgments.

18. I have sometimes doubted my ability as a lover.

19. It's all right with me if some people happen to dislike me.

20. I don't always know the reasons why I do the things I do.

21. I sometimes tell lies if I have to.

22. I never cover up my mistakes.

23. There have been occasions when I have taken advantage of someone.

24. I never swear.

25 . I sometimes try to get even rather than forgive and forget.

26. I always obey laws, even if I'm unlikely to get caught.

27. I have said something bad about a friend behind his or her back.

28. When I hear people talking privately, I avoid listening.

29. I have received too much change from a salesperson without telling him or her.

30. I always declare everything at customs.

31 . When I was young I sometimes stole things.

32. I have never dropped litter on the street

33. I sometimes drive faster than the speed limit

34. I never read sexy books or magazines. 
35. I have done things that I don't tell other people about.

36. I never take things that don't belong to me.

37. I have taken sick-leave from work or school even though I wasn't really sick.

38. I have never damaged a library book or store merchandise without reporting it.

39. I have some pretty awful habits.

40. I don't gossip about other people's business.

\section{Creative Behavior Inventory}

Indicate if you have done each of the activities or accomplishments in your adolescent and adult life never, once or twice, 3-5 times, or more than 5 times.

1. Received an award for acting

2. Worked as an editor for a school or university literary publication

3. Worked as an editor for a newspaper or similar organization

4. Constructed something that required scientific knowledge such as a radio, telescope, scientific apparatus, etc. (excluding school or university course work)

5. Painted an original picture (excluding school or university course work)

6. Entered a speech contest

7. Designed and made your own greeting cards

8. Gave a recital

9. Presented an original mathematics paper to a professional or special interest group

10. Founded a literary magazine or similar publication

11. Made a craft out of metal (excluding school or university course work)

12. Made candles

13. Knitted or crocheted something (excluding school or university course work)

14. Put on a puppet show

15. Made your own holiday decorations

16. Built a hanging mobile (excluding school or university course work)

17. Received an award for performance in modern dance or ballet

18. Received an award for performance in popular dance

19. Had a mathematics paper published

20. Made a sculpture (excluding school or university course work)

21. Had original music published or publicly performed

22. Had a piece of literature (e.g., poem, short stories, etc.) published in a school or university publication

23. Developed an experimental design (excluding school or university course work)

24. Wrote poems (excluding school or university course work)

25 . Wrote a play (excluding school or university course work)

26. Entered a project or paper into a science contest

27. Received an award for an artistic accomplishment

28. Received an award for making a craft

29. Made a craft out of plastic, plexiglass, stained glass, or a similar material (excluding school university course work)

30. Made cartoons 
31. Made a leather craft (excluding school or university course work)

32. Made a ceramic craft (excluding school or university course work)

33. Wrote music for one instrument (excluding school or university course work)

34. Wrote music for several instruments (excluding school or university course work)

35. Designed and made a piece of clothing (excluding school or university course work)

36. Cooked an original dish

37. Prepared an original floral arrangement

38. Applied math in an original way to solve a practical problem (excluding school or university course work)

39. Wrote an original computer program (excluding school or university course work)

40. Drew a picture for aesthetic reasons (excluding school or university course work)

41. Wrote the lyrics to a song (excluding school or university course work)

42. Choreographed a dance (excluding school or university course work)

43. Wrote a short story (excluding school or university course work)

44. Wrote something humorous such as jokes, limericks, satire, etc. (excluding school or university course work)

45. Planned and presented an original speech (excluding school or university course work)

46. Made jewelry (excluding school or university course work)

47. Cut a record

48. Put on a radio show

49. Had a piece of literature (e.g., poem, short story, etc.) published (not in a school or university-related publication)

50. Took and developed your own photographs (not in a school or university-related publication)

51. Performed a ballet or modern dance in a show or contest

52. Had art work or craft work publically exhibited

53. Won an award for musical accomplishments

54. Wrote clever or humorous letters

55. Designed a game

56. Directed or organized a political group

57. Won an award for a scientific project or paper

58. Performed on television

59. Assisted in the design of a set for a musical or dramatic production (excluding school or university work)

60. Had art work published in a school or university publication

61. Had a role in a dramatic production (excluding school or university work)

62. Had art work published (excluding school or university work)

63. Started but did not finish a novel (excluding school or university work)

64. Wrote and completed a novel (excluding school or university work)

65. Made or helped make a film or video tape (excluding school or university work)

66. Made a musical instrument

67. Helped design a float

68. Won an award for some achievement in literature 
69. Entered a mathematical paper or project into a contest

70. Had a scientific paper published

71. Planned and kept a garden

72. Kept a sketchbook (excluding school or university work)

73. Was a participating member of a symphony orchestra

74. Entered a contest as a singer

75. Entered a contest as a musician

76. Designed and constructed a craft out of wood (excluding school or university work)

77. Planned and directed a school or community event

78. Won an award for speech and debate

79. Wrote a play which was given in a public performance

80. Directed or managed a dramatic production

81. Designed and made a costume

82. Made up magic tricks

83. Played an instrument (percussion, including piano) with a reasonable degree of proficiency

84. Played an instrument (string) with a reasonable degree of proficiency

85. Played an instrument (brass) with a reasonable degree of proficiency

86. Played an instrument (wind) with a reasonable degree of proficiency

87. Participated in a drama workshop

88. Participated in a craft workshop, club, or similar organization (excluding school or university work)

89. Participated in a writers' workshop, club, or similar organization (excluding school or university work)

90. Participated in a dance workshop, club, or similar organization (excluding school or university work) 


\title{
APPENDIX B \\ LETTER OF INTRODUCTION AND INFORMED CONSENT
}

Illinois State University

Department of Psychology

\section{Informed Consent}

\section{Principal Investigators: Dr. Joel Schneider}

\begin{abstract}
PLEASE READ THIS DOCUMENT CAREFULLY. SIGN YOUR NAME BELOW ONLY IF YOU AGREE TO PARTICIPATE AND YOU FULLY UNDERSTAND YOUR RIGHTS. YOUR SIGNATURE IS REQUIRED FOR PARTICIPATION IN THIS RESEARCH. YOU MUST BE 18 YEARS OF AGE TO PARTICIPATE. IF YOU DESIRE A COPY OF THIS CONSENT FORM, YOU MAY REQUEST ONE AND WE WILL PROVIDE IT.
\end{abstract}

Description of the Study: This study will ask you to complete several surveys regarding your personality, how you would describe yourself, your life achievements, opinions on several topics, word associations, and general information about yourself. You will also be asked to evaluate situations where someone behaved dishonestly by creating possible explanations for the behavior. We are also interested in your opinion of how acceptable it would be to act dishonestly in those situations.

Nature of Participation: You will spend approximately 45 minutes to an hour completing the surveys and the activities.

Purpose of the Study: The purpose of the study is to better understand between opinions about dishonest behaviors, justifications for those behaviors, and an individual's characteristics.

Possible Risks: Overall, we do not expect any large risks based on the contents of the surveys. There may be a slight risk of negative emotions when asked think about dishonest behaviors. This risk is not more than what you would likely encounter in your day to day life.

Possible Benefits: As a possible benefit to this study, you may find the experience interesting or may inadvertently gain valuable self-knowledge.

Compensation for your time: You will receive extra credit in a psychology course. You will receive extra credit simply by virtue of coming to your appointment; you are free to withdraw your participation at any time without penalty.

Confidentiality: Your questionnaire packet has been assigned a code number that will protect your identity. All data will be kept in secured files, in accord with the standards of the University, Federal regulations, and the American Psychological Association. Finally, it is no individual person's responses that interest us; we are studying people in general. 
Opportunities to Question: Any technical questions about this research may be directed to Dr. William Joel Schneider at 438-8410. Any questions regarding your rights as a research participant or research-related injuries may be directed to ISU's Office of Research Ethics and Compliance (309) 4382520 .

Opportunities to Withdraw at Will: If you decide now or at any point to withdraw this consent or stop participation, you are free to do so at no penalty to yourself. You are free to skip specific questions and continue participating at no penalty.

Opportunities to be Informed of Results: In all likelihood, the results will be fully available around the May 2015. If you wish to be told the results of this research, please contact Dr. Joel Schneider 309-438-8410. He will either meet with you to discuss the results or direct you to a copy of the results. In addition, there is a chance that the results from this study will be published in a scientific psychology journal, which would be available in many libraries. In such an article, participants would be identified in general terms such as "college students."

I consent to participate in this study. I further acknowledge that I have received an offer to obtain a copy of this consent form. 


\section{APPENDIX C DEBRIEFING STATEMENT}

Psychological researchers have found that people who report being more creative also tend to engage in higher levels of dishonest behavior. It is not yet known why this finding occurs. We are investigating the question as to whether creative people can fluently think of more reasons to be dishonest.

If you would like to know the results of this study, you may contact the principal investigator, Joel Schneider at (309) 438-8410, or wjschne@ilstu.edu.

If participating in this study has caused you discomfort, please be aware that you can contact the principal investigator, Joel Schneider at (309) 438-8410, or wjschne@ilstu.edu. You may also contact the ISU Student Counseling Services (4383655 , in the Student Services Building) for free counseling and consultation. 